\title{
Quasi-stationary waves in the Southern Hemisphere during El Niño and La Niña events
}

\author{
V. Brahmananda Rao, J. P. R. Fernandez, and S. H. Franchito \\ Centro de Previsão de Tempo e Estudos Climáticos, CPTEC. Instituto Nacional de Pesquisas Espaciais, INPE. CP 515, \\ 12201-970, São José dos Campos, SP, Brazil.
}

Received: 26 February 2003 - Revised: 31 July 2003 - Accepted: 4 September 2003 - Published: 19 March 2004

\begin{abstract}
Characteristics of quasi-stationary (QS) waves in the Southern Hemisphere are discussed using 49 years (1950-1998) of NCEP/NCAR reanalysis data. A comparison between the stationary wave amplitudes and phases between the recent data (1979-1998) and the entire 49 years data showed that the differences are not large and the 49 years data can be used for the study. Using the 49 years of data it is found that the amplitude of QS wave 1 has two maxima in the upper atmosphere, one at $30^{\circ} \mathrm{S}$ and the other at $55^{\circ} \mathrm{S}$. QS waves 2 and 3 have much less amplitude. Monthly variation of the amplitude of QS wave 1 shows that it is highest in October, particularly in the upper troposphere and stratosphere.

To examine the QS wave propagation Plumb's methodology is used. A comparison of Eliassen-Palm fluxes for El Niño and La Niña events showed that during El Niño events there is a stronger upward and equatorward propagation of QS waves, particularly in the austral spring. Higher upward propagation indicates higher energy transport. A clear wave train can be identified at $300 \mathrm{hPa}$ in all the seasons except in summer. The horizontal component of wave activity flux in the El Niño composite seems to be a Rossby wave propagating along a Rossby wave guide, at first poleward until it reaches its turning latitude in the Southern Hemisphere midlatitudes, then equatorward in the vicinity of South America. The position of the center of positive anomalies in the austral spring in the El Niño years over the southeast Pacific, near South America, favors the occurrence of blocking highs in this region. This agrees with a recent numerical study by Renwick and Revell (1999).
\end{abstract}

Key words. Meteorology and atmospheric dynamics (climatology; general circulation; ocean-atmosphere interactions)

Correspondence to: V. Brahmananda Rao

(vbrao@cptec.inpe.br)

\section{Introduction}

Any meteorological variable, $\phi$ (for example, geopotential height) can be divided into a time mean and a time deviation: $\phi(\lambda, \varphi, z, t)=\phi_{0}(\lambda, \varphi, z)+\phi^{\prime}(\lambda, \varphi, z, t)$, where $\lambda, \varphi, z$ and $t$ are, respectively, longitude, latitude, height and time. $\phi^{\prime}$ is termed as the transient circulation (eddies) and is responsible for weather. $\phi_{0}$ can be divided further into a zonal mean and a zonal deviation: $\phi_{0}(\lambda, \varphi, z)=\phi_{00}(\varphi, z)+\phi^{*}(\lambda, \varphi, z) . \phi_{00}$ represents the stationary symmetric circulation and is popularly known as the Hadley type circulation. $\phi_{00}$ also represents a zonal flow. $\phi^{*}$ is the asymmetric stationary circulation and is popularly known as stationary waves. Since the stationary waves can change a little (in time) in position and intensity, these are called quasi-stationary (QS) waves. This is the subject of the present paper.

QS waves are forced by inhomogenities in the Earth's surface: orography (Charney and Eliassen, 1949), land-sea contrast (Smagorinsky, 1953), etc. and are observed throughout the globe over a wide range of length scales. Also, the transient part $\phi^{\prime}$ interacts with the QS waves and might force them (Holopainen, 1978; Holopainen et al., 1982). Most of the research on QS waves emphasized the Northern Hemisphere (NH). A few studies have been made discussing QS waves in the Southern Hemisphere (SH). van Loon and Jenne (1972), Hartmann (1977), Trenberth (1980) and Karoly (1989) discussed QS waves during winter and summer. Randel (1988) studied QS waves in the SH in the other seasons as well. He noted that the QS waves' variance has maxima at $30^{\circ}-40^{\circ} \mathrm{S}$ and $50^{\circ}-60^{\circ} \mathrm{S}$, in the upper troposphere during the late winter or early spring. He also noted that the maxima in the stratosphere occurred in the latitude band $50^{\circ}-60^{\circ} \mathrm{S}$. QS wave number 1 dominated the field, and the momentum and heat transports. Quintanar and Mechoso (1995) used the NMC (National Meteorological Center) analysis for the period January 1979 through December 1990 to discuss the QS waves in the SH. They found that the QS wave 1 in winter is by far the most dominant part of the geopotential height field in both the troposphere and stratosphere. 
Table 1. El Niño and La Niña years.

\begin{tabular}{lllll}
\hline & Summer (DJF) & Autumn (MAM) & Winter (JJA) & Spring (SON) \\
\hline El Niño & 1958,1959, & 1953,1957, & 1953,1957, & 1951,1957, \\
& 1966,1969, & 1958,1966, & 1958,1963, & 1958,1963, \\
& 1970,1973, & 1969,1972, & 1965,1966, & 1965,1968, \\
& 1978,1980, & 1982,1983, & 1969,1972, & 1969,1972, \\
& 1983,1987, & 1987,1991, & 1982,1986, & 1976,1977, \\
& 1988,1991, & 1992,1993, & 1987,1990, & 1982,1986, \\
& 1992,1993, & 1997,1998 & 1991,1992, & 1987,1990, \\
& 1995,1998 & & 1993,1994, & 1991,1992, \\
& & 1997 & 1993,1994, \\
\hline \multirow{2}{*}{ La Niña } & 1950,1951, & 1950,1955, & 1950,1954, & 1950,1954, \\
& 1955,1956, & 1956,1971, & 1955,1956, & 1955,1956, \\
& 1965,1971, & 1974,1975, & 1964,1971, & 1964,1970, \\
& 1974,1975, & 1984,1985, & 1973,1974, & 1971,1973, \\
& 1976,1984, & 1989 & 1975,1988 & 1974,1975, \\
& 1985,1989, & & 1998 & 1983,1984, \\
& 1996 & & & 1988,1995
\end{tabular}

More recently, Hurrell et al. (1998) discussed the characteristics of stationary waves in the $\mathrm{SH}$, and Kiladis and Mo (1998) discussed their interannual variability. As in Randel (1988), Hurrell et al. (1998) found that at $500 \mathrm{hPa}$ wave 1 reaches its peak between $50^{\circ} \mathrm{S}$ and $60^{\circ} \mathrm{S}$ in both winter and summer. They noted that wave 1 over the southern oceans closely follows the pattern of the latitude anomalies of temperature, suggesting the importance of surface thermal forcing. Hurrell et al. (1998) also found that the interannual variability is largest in the Pacific, where the influence of the southern oscillation is highest.

Kiladis and Mo (1998) studied the interannual variability of QS waves in the SH using empirical orthogonal function (EOF) analysis. The wave train-like nature of these EOF modes (see Fig. 8.3c of Kiladis and Mo, 1998) suggests the propagation of Rossby wave energy with a source region in the subtropics. Seasonal composite of $500 \mathrm{hPa}$ height anomalies for warm (El Niño) events (see Fig. 8.4 of Kiladis and Mo, 1998) also strongly suggests the Rossby wave propagation. A ridge in the southeast Pacific associated with the wave train during the warm events is favorable for blocking in this region and the reverse happens during cold events. Rutllant and Fuenzalida (1991) and Marques and Rao (2000) showed the connection between blocking over the southeast Pacific and ENSO (El Niño-Southern Oscillation). Using a barotropic numerical model, Renwick and Revell (1999) showed that the tropical convective heating associated with the OLR (outgoing longwave radiation) anomaly, presumably generated during ENSO events, forces a Rossby wave train which is responsible for higher blocking over the southeast Pacific during El Niño events. In the present study we propose to test the hypothesis of Renwick and Revell (1999) observationally. We use Plumb's (1985) approach to examine the three-dimensional propagation of QS waves in the $\mathrm{SH}$, giving emphasis for the El Niño and La Niña events.

\section{Data source and methodology}

In the present study we use monthly mean values of the geopotential height $\phi$ for the period 1950-1998. These data were obtained from NCEP (National Centers for Environmental Predictions)/NCAR (National Center for Atmospheric Research) reanalysis and are available at 1000, 925, $850,700,600,500,400,300,250,200,150,100,70,50,30$, 20 and $10 \mathrm{hPa}$ levels, at $2.5^{\circ} \times 2.5^{\circ}$ (latitude $\times$ longitude) intervals. For a detailed description of the NCEP/NCAR data assimilation method, see Kalnay et al. (1996).

In our case time mean is taken over a period of three months. We can write the zonal wave components for $\phi^{*}$ as:

$\phi^{*}{ }_{k}(\lambda, \varphi, p)=A_{k}(\varphi, p) \cos \left[\left(k \lambda+\alpha_{k}(\varphi, \mathrm{p})\right)\right]$,

where $\mathrm{k}$ is the wave number, $A_{k}$, the amplitude and $\alpha_{k}$ is the phase. In our case, $k=1,20$.

The values of temperature $T$, zonal $(u)$ and meridional $(v)$ wind component for the same period are obtained using the method given by Randel $(1987,1988)$. In this method, the geopotential heights are harmomically analysed based on the zonal wave number. Fluxes of heat and momentum are evaluated using winds derived via the linearized zonal and meridional momentum equations. Eliassen-Palm (EP) flux divergences are calculated from the primitive equation expressions, neglecting terms involving the vertical velocity. EP flux vectors are scaled with the inverse square root of 
a) DJF

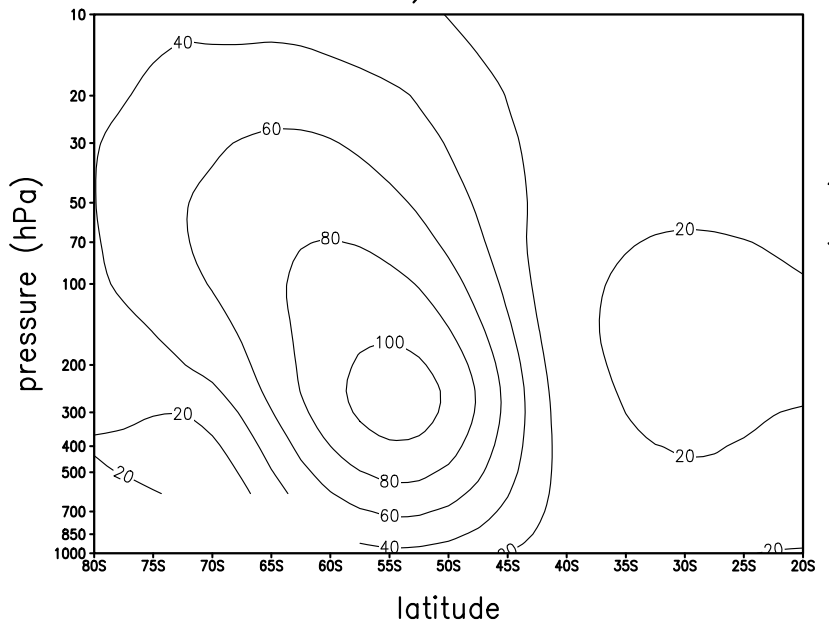

c) JJA

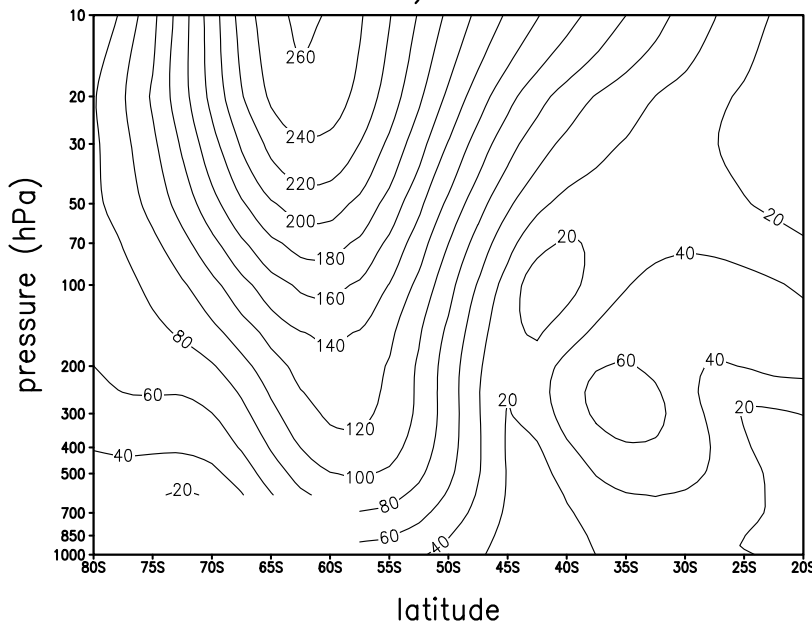

b) MAM

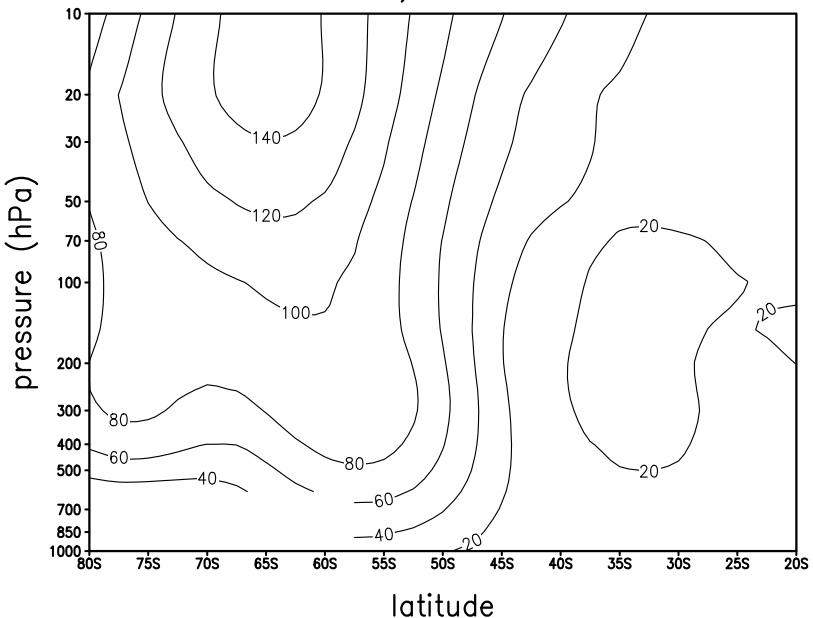

d) $\mathrm{SON}$

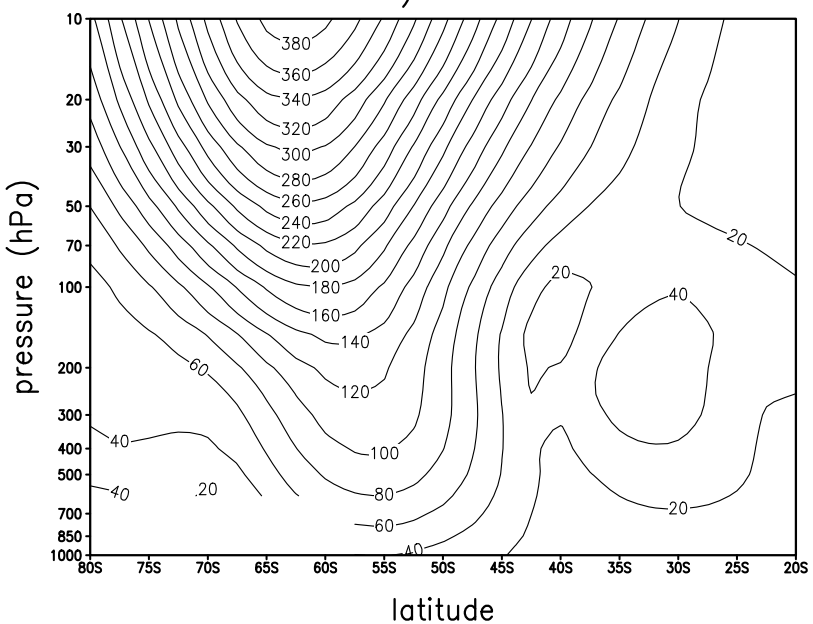

Fig. 1. Amplitudes of QS wave 1 (m) in the data set for the period 1950-1998 for: (a) DJF, (b) MAM, (c) JJA and (c) SON. Contour interval is $20 \mathrm{~m}$.

density, in order to make them visible throughout the stratosphere. The differences are small if the wind and temperature from NCEP/NCAR reanalysis data are directly used.

The list of El Niño and La Niña episodes was obtained from NCEP (http://www.cpc.noaa.gov/products/ analysis_monitoring/ensostuff/). For compiling this list it was attempted to classify the intensity of each event by focusing on a key region of the tropical Pacific (along the equator from $150^{\circ} \mathrm{W}$ to the date line). The process of classification was primarily subjective using reanalyzed sea surface temperature (SST) analyses produced at the NCEP/Climate Prediction Center (CPC) and at the United Kingdom Meteorological Office. In the period considered (1950-1998) there are $16 \mathrm{El}$ Niño summers (December, January and February) and $13 \mathrm{La}$ Niña summers. There are $14 \mathrm{El}$ Niño autumns (March, April and May) and 9 La Niña autumns. There are 17 El Niño winters (June, July and August) and 11 La Niña winters. Finally, there are $19 \mathrm{El}$ Niño springs (September, October and November) and 15 La Niña springs. The list of these years is given in Table 1.

\section{Characteristics of QS waves}

In the present study we used data from 1950 through 1998. Before the advent of meteorological satellites the data were sparse in the SH. Thus, it would be necessary to verify the differences in characteristics of QS waves in the data for 1950-1998 and in recent data. Figure 1 shows the amplitude of QS wave 1 for different seasons for the periods 1950 through 1998. The corresponding amplitude values for the period 1979 through 1998 are shown in the Appendix (Fig. A1). The magnitude and distribution of the amplitudes of wave 1 in DJF and MAM are very similar in both data sets. Although the distribution in JJA and SON is very similar, the magnitude is slightly higher in spring in the recent data. The differences in amplitudes of wave 1 between the two periods are not entirely due to the improvement of data coverage in recent years. Part of the differences could be due to natural interannual variability.

Figure 2 shows the phase of wave 1 in the period 1950 through 1998. The phase of wave 1 in the recent data set 
a) DJF

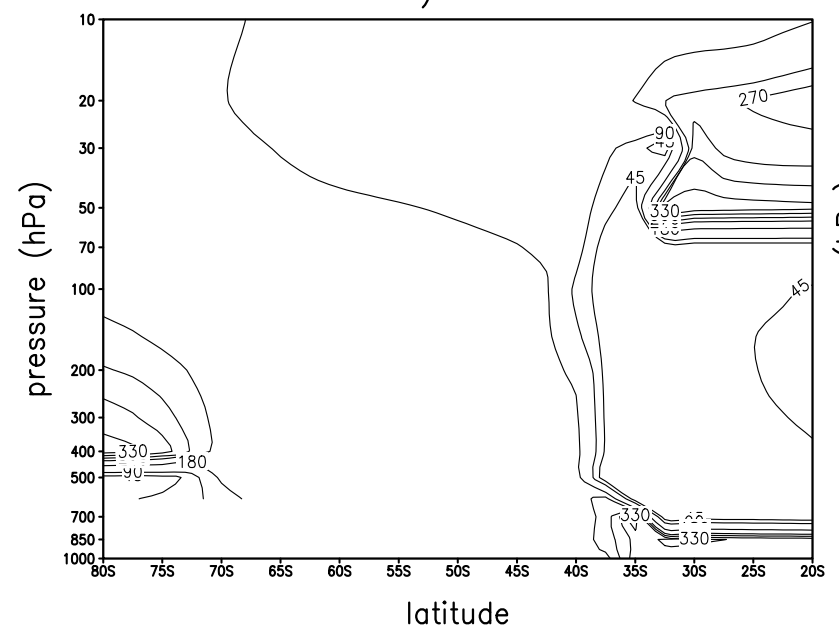

c) JJA

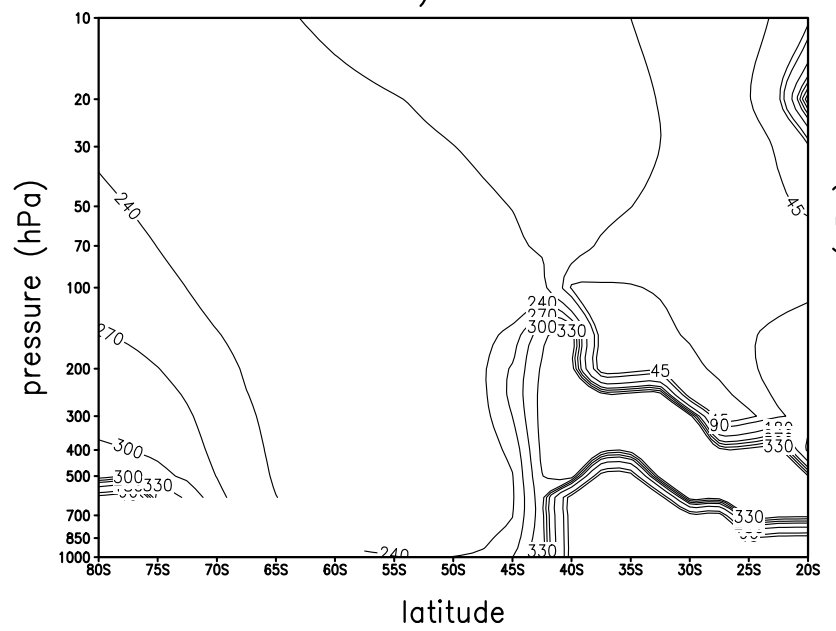

b) MAM

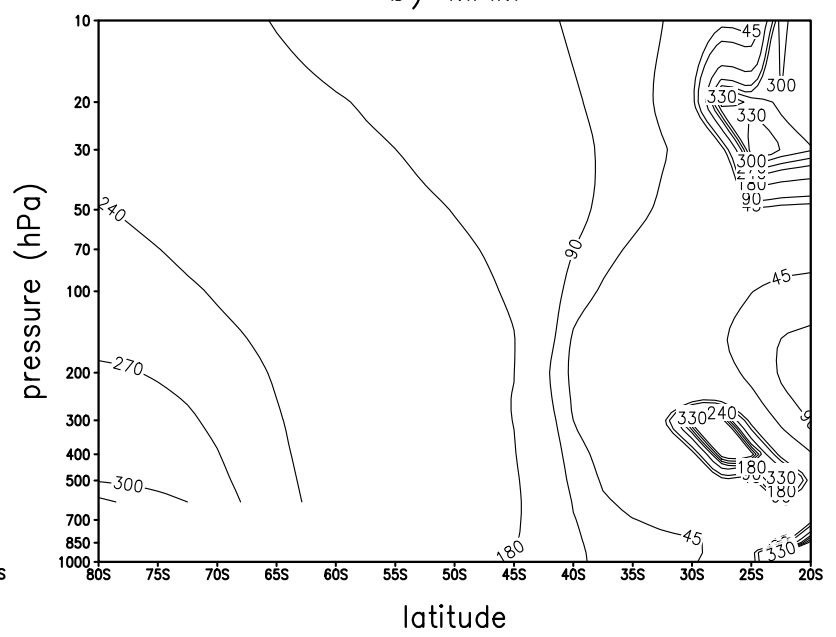

d) SON

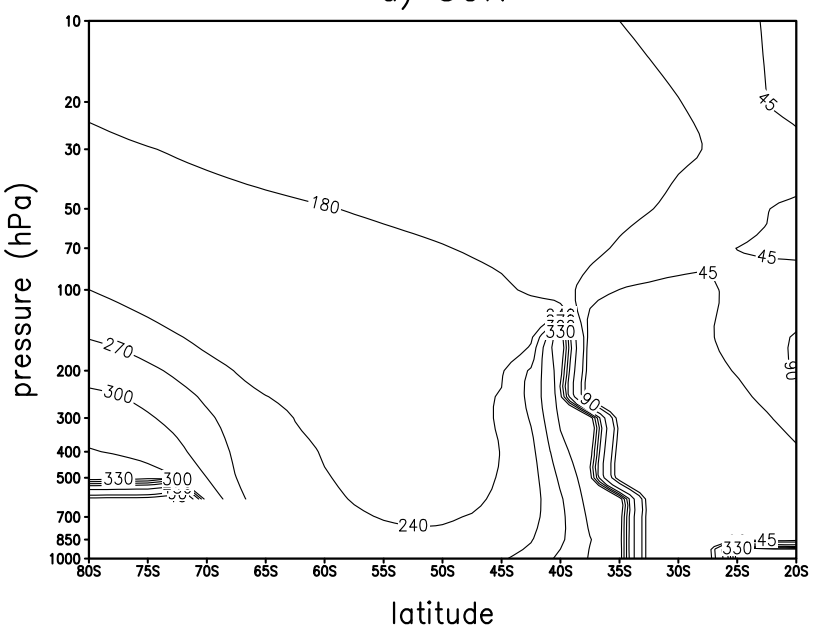

Fig. 2. Same as Fig 1, but for the phase (degrees).

is shown in the Appendix (Fig. A2). The phase distribution is also very similar, except for a small difference in summer, when the amplitude of wave 1 is weakest. Amplitudes of waves 2 and 3 (figures not shown) are also very similar in magnitude and distribution. The amplitude of wave 2 is slightly less and that of wave 3 is slightly more in the recent data set. The distribution and magnitude of wave 3 is very similar in both data sets. The phases of waves 2 and 3 are similar in winter in both data sets and slightly different in other seasons. Wave 1 explains about $90 \%$ of the total variance in the geopotential field and all other waves (mostly waves 2 and 3) together explain the remaining 10\%. Since the most dominant characteristics of amplitude and phase, particularly of wave 1, are similar in the data set for 19501998 and in the recent data set for 1979-1998, we propose to use the total period of 49 years to study the characteristics of stationary waves in the $\mathrm{SH}$.

Figure 1 shows several interesting characteristics. In summer in the upper troposphere there are two maxima, one at $30^{\circ} \mathrm{S}$ and another at $55^{\circ} \mathrm{S}$. The value in the higher latitudes is much larger than that in the subtropics. A comparison with the values in other seasons shows that the QS wave 1 is trapped in the lower atmosphere in summer, while in other seasons it propagates into the stratosphere. In spring the amplitude values in the lower stratosphere are highest.

The amplitudes of QS waves 2 and 3 (figures not shown) are much less than that of wave 1 . It is known that these waves (wave 2 and 3 ) are primarily eastward moving (Mechoso and Hartman, 1982). QS wave 2 is confined to the lower atmosphere in DJF, whereas in other seasons it propagates into the lower stratosphere. QS wave 3 is essentially confined to the lower atmosphere in all the seasons. The maximum value is about $50 \mathrm{~m}$ in the lower stratosphere for wave 2 and $30 \mathrm{~m}$ for wave 3 in spring. In the upper troposphere, however, the amplitude of wave 3 in all four seasons is more (about $30 \mathrm{~m}$ ) than that of wave 2 (about $10 \mathrm{~m}$ ). The seasonal evolution of QS waves can be understood in terms of the linear wave theory (Charney and Drazin, 1961). The 


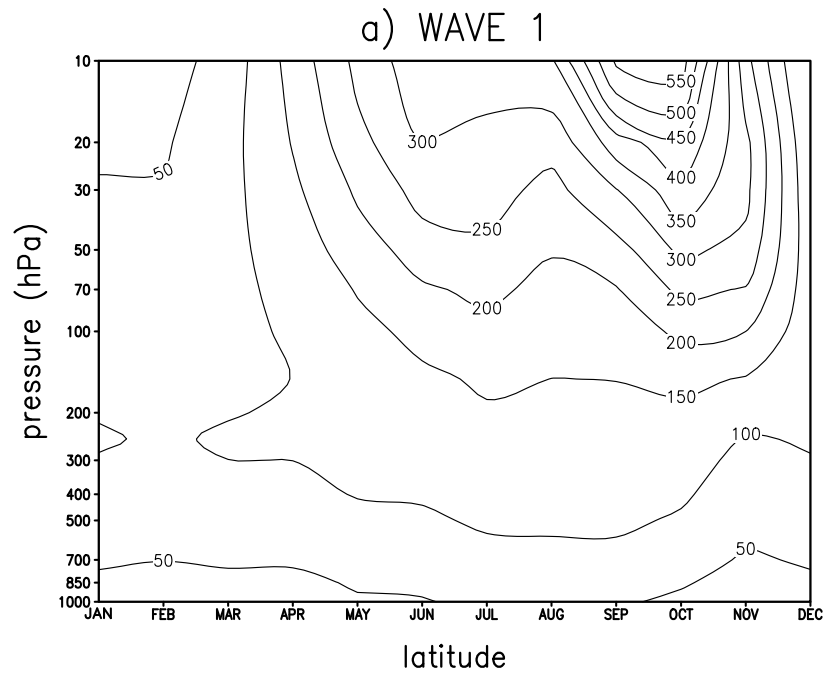

b) WAVE 2

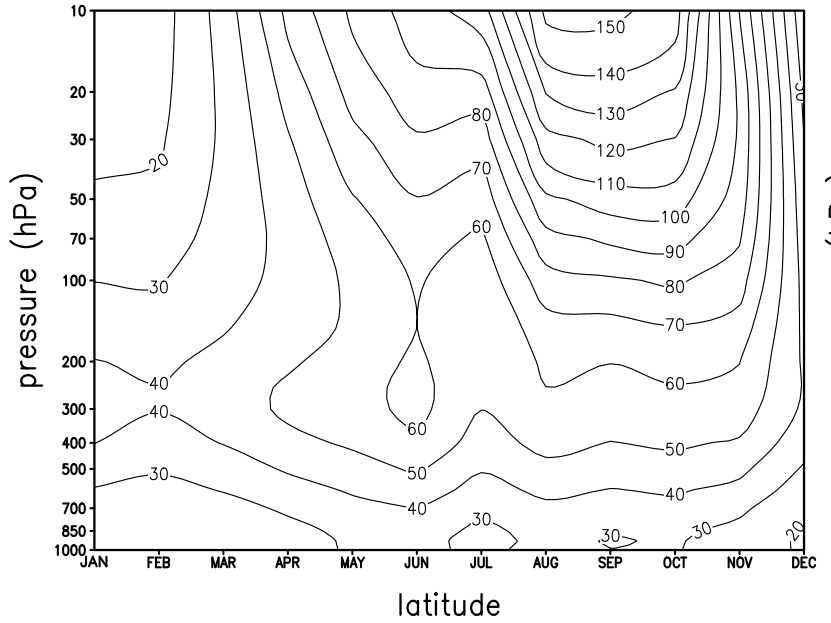

c) WAVE 3

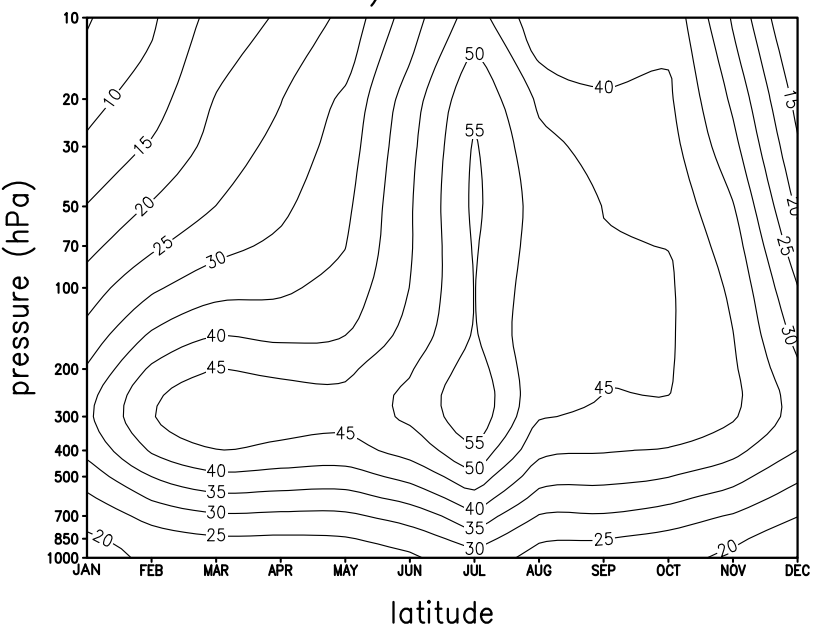

Fig. 3. Monthly variation of the amplitudes (m) of QS waves 1 (a), 2 (b) and 3 (c) at $60^{\circ} \mathrm{S}$. Contour interval is : (a) $50 \mathrm{~m}$, (b) $10 \mathrm{~m}$, and (c) $5 \mathrm{~m}$.

presence of easterlies in the stratosphere in DJF (figure not shown) does not permit the vertical propagation of QS waves, (Charney and Drazin, 1961). Again, in JJA the strong westerlies are not favorable for vertical propagation. The decreasing of westerlies in spring is favorable for the vertical propagation of QS waves and this propagation is connected to the final warming in the SH stratosphere. From Fig. 2 it can be seen that the phase angle of wave 1 does not change much in the lower troposphere, while in the upper troposphere and stratosphere it decreases with height, indicating a westward inclination. Westward inclination is better defined in winter and spring. This westward inclination is associated with poleward heat transport and vertical propagation.

Figure 3 shows the monthly variation of amplitude of QS waves 1,2 and 3 at $60^{\circ} \mathrm{S}$. At this latitude, the maximum amplitude $(100 \mathrm{~m})$ of QS wave 1 , in the troposphere is in August, and the maximum amplitude in the stratosphere is in October $(550 \mathrm{~m})$. In the stratosphere there is a secondary maximum in July $(300 \mathrm{~m})$. The lowest value of amplitudes of
QS wave 1 is found in summer $(50 \mathrm{~m})$. The monthly variation of the amplitude of QS wave 2 is similar to that of QS wave 1 except that the amplitudes are less and in the stratosphere in October they are about the same as those of QS wave 1 .

The monthly variation of QS wave 3 is very different. A clear winter (July) maximum is found both in troposphere and stratosphere. Compared to QS waves 1 and 2 the amplitudes of QS wave 3 are much less. As we have seen earlier (Fig. 3), QS wave 3 is essentially trapped in the troposphere and lower stratosphere. Thus, from the above discussion we can infer the contribution of QS wave 1 for the zonal variance of $\phi^{*}$ is by far the most dominant.

Hurrell et al. (1998) also discussed the observed characteristics of stationary waves. However, they described the features of wave number 1 in summer and winter seasons only. Although the amplitude of wave number 1 in summer is comparable to our values, in winter our values are much higher. The other features are similar. 
a) DJF

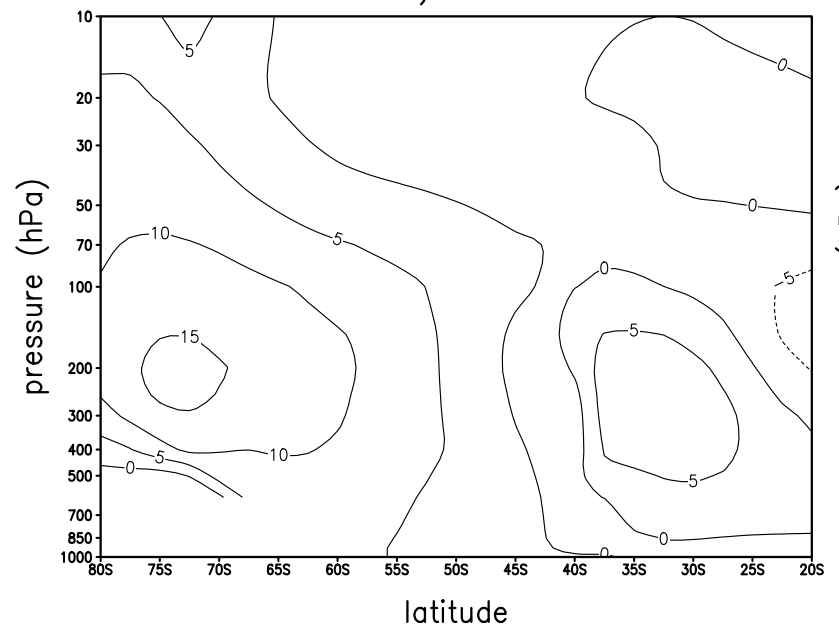

c) JJA

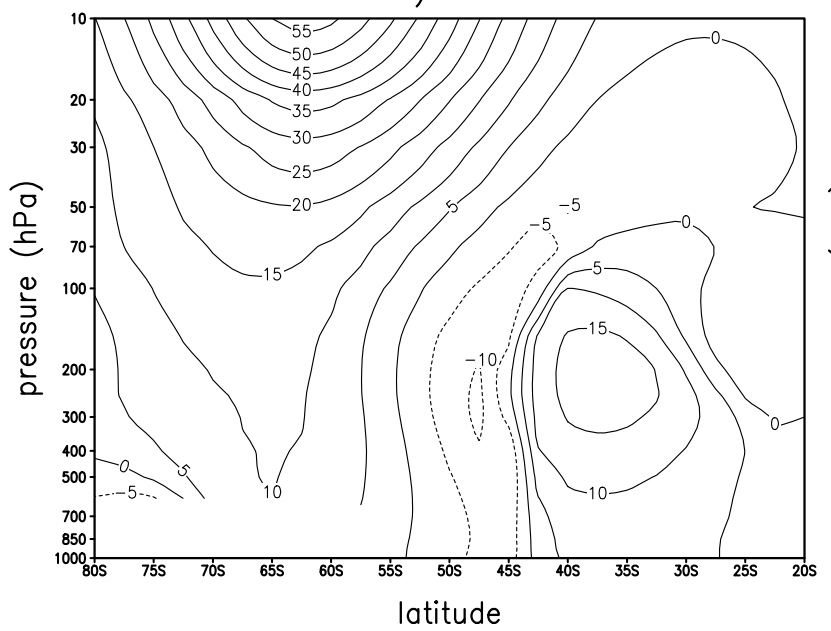

b) MAM

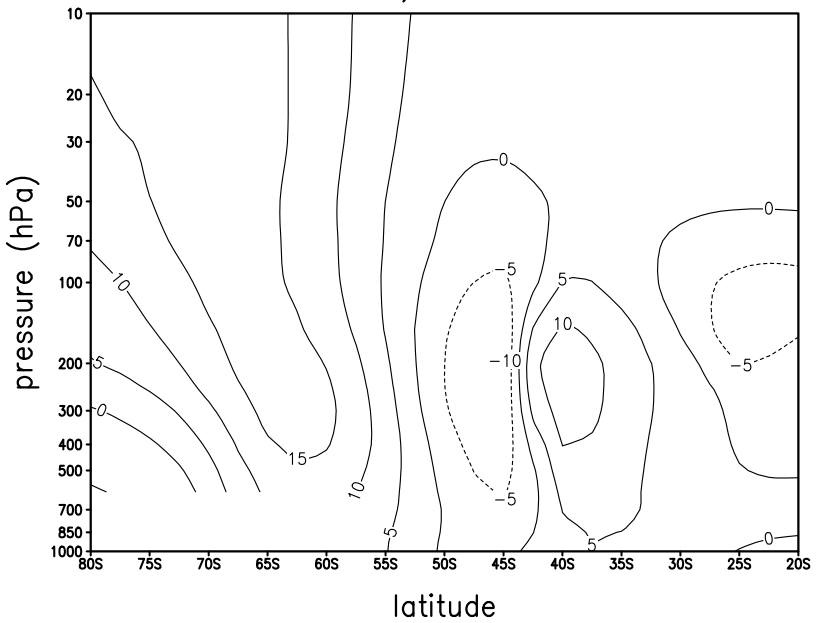

d) SON

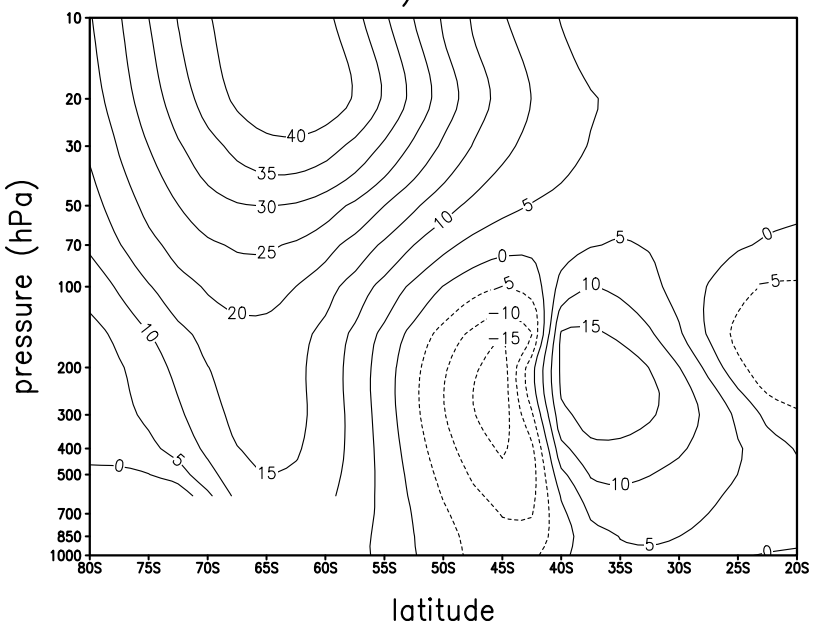

Fig. 4. Difference of amplitude of QS wave 1 (m) between El Niño composite and the mean for: (a) DJF, (b) MAM, (c) JJA, and (d) SON. Contour interval is $5 \mathrm{~m}$.

Figure 4 shows the difference in amplitude of QS wave 1 between El Niño composite and the mean for the four seasons. The differences are small in DJF and MAM. In JJA and SON there is an increase in the higher latitudes, particularly in the stratosphere. In the mid-latitudes in the troposphere there is a slight decrease and in the subtropics there is an increase. The differences in the La Niña composite (figure not shown) are in general opposite to those of El Niño.

In the EP fluxes for El Niño and La Niña periods (figures not shown) large changes are found mostly in the highlatitude spring stratosphere. The general characteristics of the EP fluxes are similar to the known features (e.g. Edmon et al., 1980). There is mostly upward propagation of QS waves in the lower levels in mid and high latitudes and then upward and equatorward propagation in the lower stratosphere. As is well known, the upward propagation of QS waves is associated with poleward sensible heat transport and the equatorward propagation is associated with pole- ward momentum transport (Eliassen and Palm, 1961). Since the vectors of EP fluxes are parallel to the group velocity vectors, when the idea of group velocity is applicable, they represent the direction of energy propagation (Edmon et al., 1980; Eliassen and Palm, 1961). Figure 5 shows the anomalous (differences from the mean) EP fluxes for the El Niño composite. In both DJF and MAM there is mostly higher meridional propagation of QS waves with large values in the mid-latitudes in the upper troposphere. In JJA there is higher upward propagation in the high latitudes. It is seen that the fluxes are the largest in SON. In SON there is higher upward propagation in the high latitudes and higher meridional propagation in the midlatitudes with high values in the lower stratosphere. Figure 6 shows the differences between El Niño and La Niña periods. During El Niño there seems to be larger equatorward focussing of QS waves. This is consistent with a larger poleward transport of momentum (figures not shown) during El Niño periods. At lower latitudes from $20^{\circ} \mathrm{S}$ up to 
a) DJF

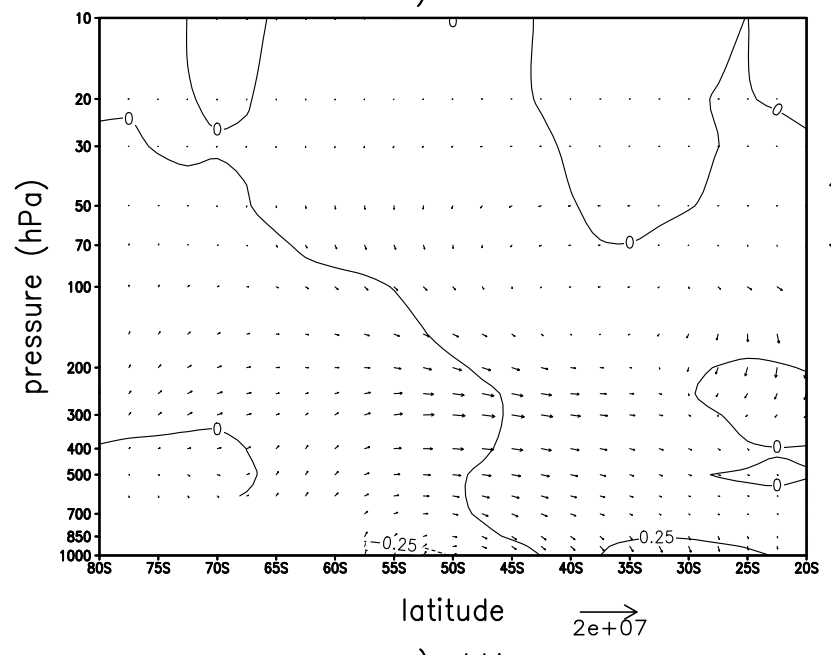

c) JJA

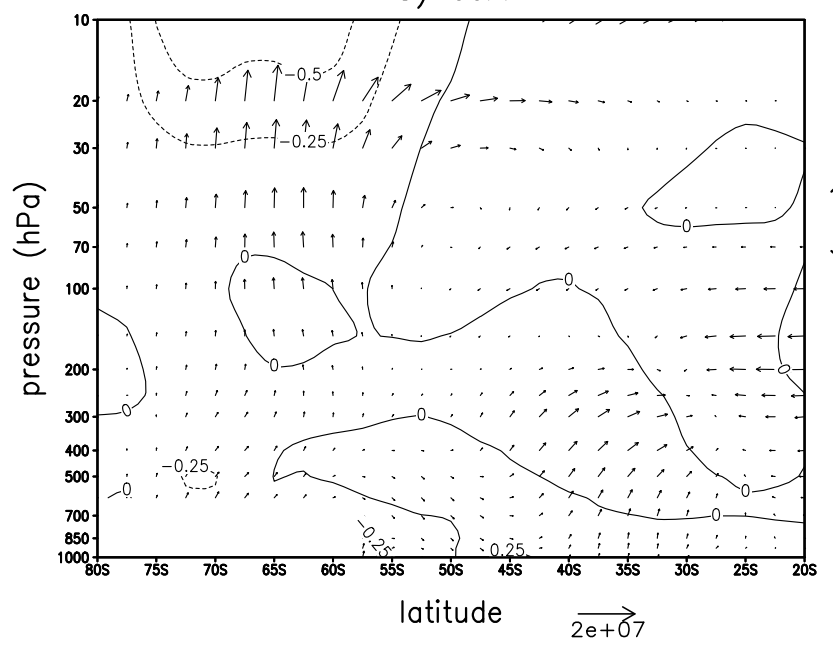

b) MAM

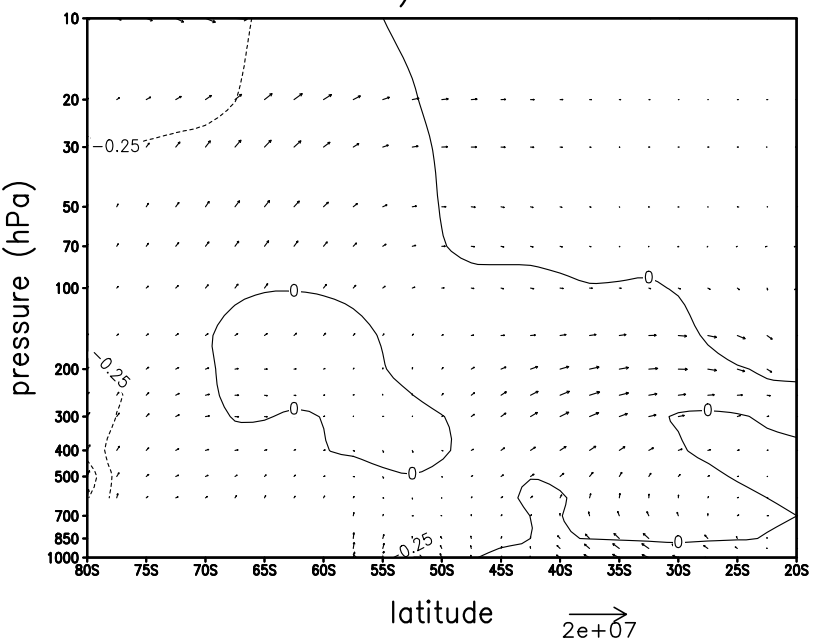

d) SON

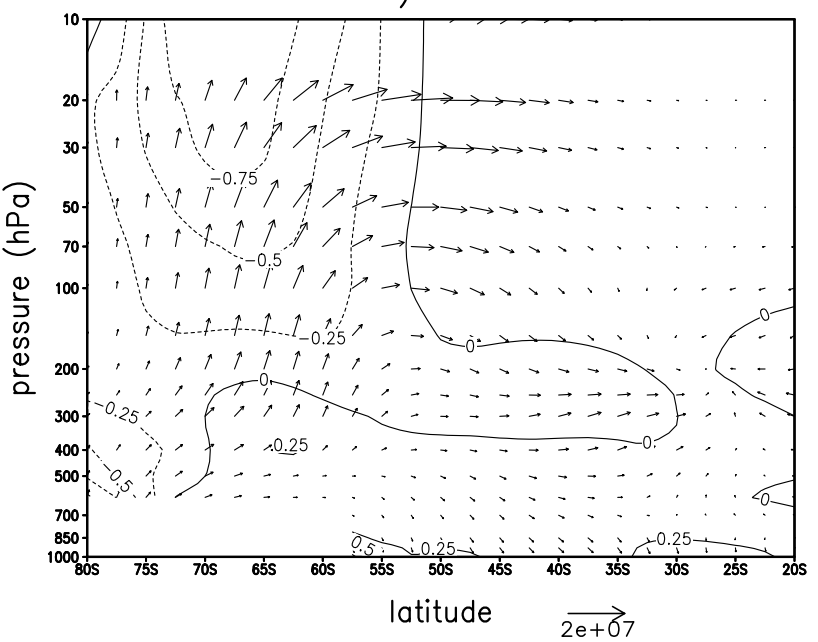

Fig. 5. Zonally-averaged EP flux cross sections for El Niño composite minus the mean for: (a) DJF, (b) MAM, (c) JJA, and (d) SON. Lines indicate divergence of EP flux. The horizontal arrow scale for EP flux is in units of $\mathrm{m}^{3} \mathrm{~s}^{-2}$ and indicated at the bottom of the figures. The EP divergence contour interval is $0.25 \mathrm{~m} \mathrm{~s}^{-1}$ day $^{-1}$.

about about $35^{\circ} \mathrm{S}$, there is a larger poleward propagation of QS waves in the upper troposphere during El Niño periods in all seasons. Another interesting feature is a larger upward focussing of QS waves in the upper troposphere in the latitudes $50^{\circ}-65^{\circ} \mathrm{S}$ and larger equatorward focussing in spring in the stratosphere.

\section{Propagation of QS waves in the SH during El Niño and La Niña events}

We will use the approach introduced by Plumb (1985) to study the QS wave propagation. This approach has been extensively used in both model and observational studies (Karoly et al., 1989; Lau and Peng, 1992; Schubert et al., 1993; Quintanar and Mechoso, 1995). For small-amplitude waves on a zonal mean flow, the conservation relationship for stationary wave activity (Plumb, 1985) may be written as

$$
\partial A_{s} / \partial t+\nabla \cdot \boldsymbol{F}_{\boldsymbol{s}}=C_{s}
$$

where $A_{s}$ is the stationary wave activity,

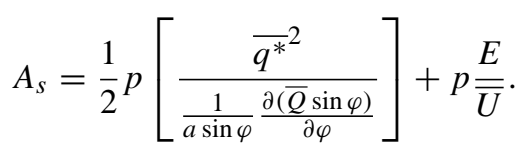

$\boldsymbol{F}_{\boldsymbol{s}}$ is the three-dimensional flux of stationary wave activity,

$$
\begin{aligned}
\boldsymbol{F}_{\boldsymbol{s}} & =p \cos \varphi\left\{{\overline{v^{*}}}^{2}-\frac{1}{2 \Omega a \sin 2 \varphi} \frac{\partial\left(\overline{v^{*}} \overline{\phi^{*}}\right)}{\partial \lambda},\right. \\
& -\overline{u^{*}} \overline{v^{*}}-\frac{1}{2 \Omega a \sin 2 \varphi} \frac{\partial\left(\overline{u^{*}} \overline{\phi^{*}}\right)}{\partial \lambda},
\end{aligned}
$$


a) DJF

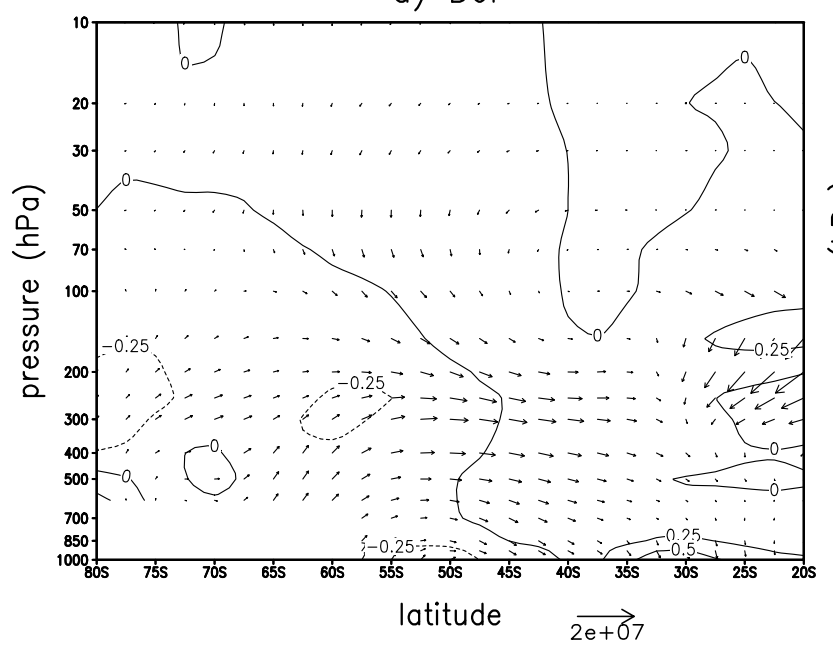

c) JJA

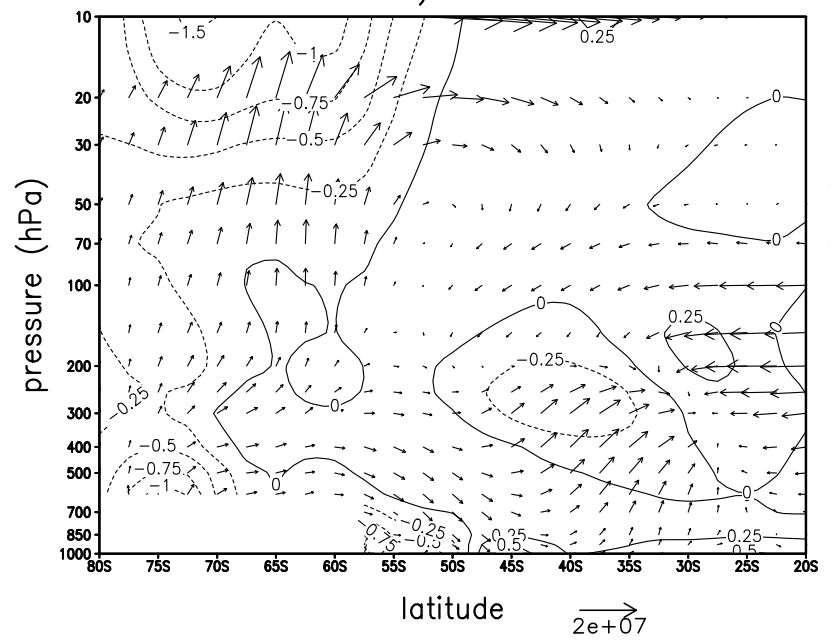

b) MAM

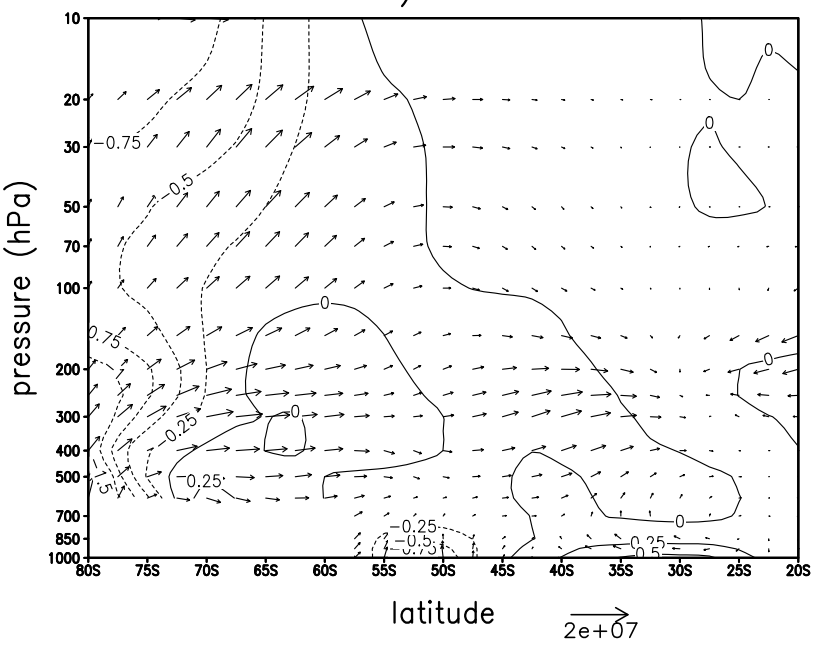

d) $\mathrm{SON}$

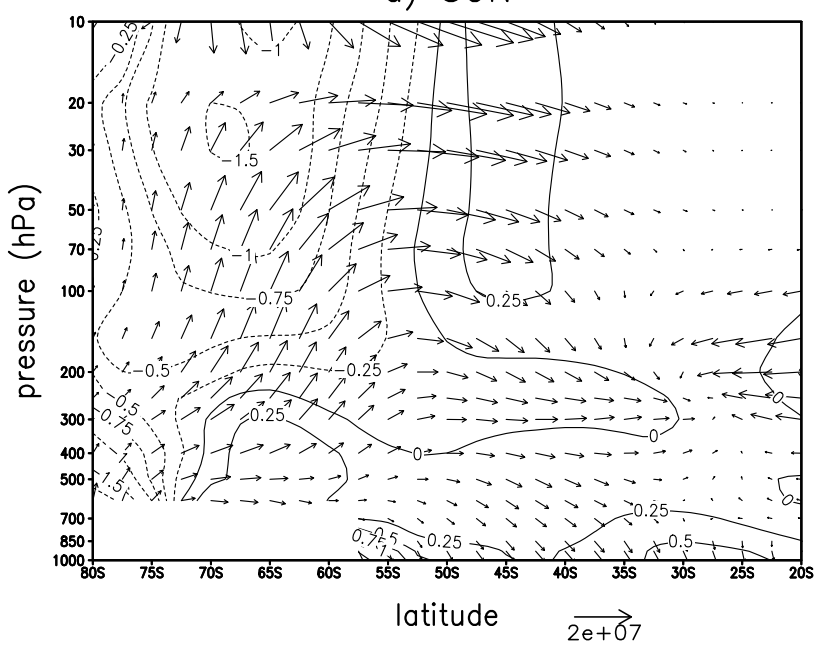

Fig. 6. Same as Fig. 5, but for El Niño minus La Niña.

$$
\left.\frac{2 \Omega \sin \varphi}{S}\left[\overline{v^{*}} \overline{T^{*}}-\frac{1}{2 \Omega a \sin 2 \varphi} \frac{\left(\overline{T^{*}} \overline{\phi^{*}}\right)}{\partial \lambda}\right]\right\}
$$

and $C_{s}$ is a nonconservative source-sink term that includes diabatic and frictional effects and interactions with transient eddies. The overbar represents a time-average and the quantities with asterisks denote departures from the zonal average; $p$ is the pressure, $Q$ and $q^{*}$ are the zonal mean and perturbation quasi-geostrophic potential vorticity, $U$ is the zonal mean flow, $E$ is the wave energy density, $u^{*}$ and $v^{*}$ are the eddy zonal and meridional geostrophic wind components, $a$ is the Earth's radius, $\phi$ is the geopotential, $T$ is the temperature, $\Omega$ is the angular rotation rate of the Earth and $S$ is a time and area averaged static stability.

Plumb (1985) showed that for steady, conservative waves $\boldsymbol{F}_{\boldsymbol{S}}$ is nondivergent and that for slowly varying almost plane waves, $\boldsymbol{F}_{\boldsymbol{S}}$ is parallel to the group velocity. In general, the starred (wave) quantities are evaluated from time averages (over a season) in which case the time-derivative in expres- sion (2) is relatively small and wave sources (sinks) are associated with regions where $\boldsymbol{F}_{\boldsymbol{s}}$ is divergent (convergent). Since $\boldsymbol{F}_{\boldsymbol{s}}$ is derived under the quasi-geostrophic assumption, its validity is questionable in low latitudes and also one should be careful in interpreting the short-scale quasi-stationary waves (Quintanar and Mechoso, 1995).

Figures 7 and 8 show the horizontal component of $\boldsymbol{F}_{\boldsymbol{s}}$ $\left(\boldsymbol{H}_{\boldsymbol{c}}\right)$ and the geopotential height anomalies (El Niño or La Niña minus the mean) for the El Niño and La Niña composites, respectively. Shaded areas show the significance at the 95\% confidence level. In summer (Fig. 7a) $\boldsymbol{H}_{\boldsymbol{c}}$ is generally weak compared to the other seasons. The height anomalies show a high (positive center) over southern South America and a weak low to the northwest of this. $\boldsymbol{H}_{\boldsymbol{c}}$ vectors indicate southeastward wave propagation to the west of southern South America. Divergence of vectors in this region suggests a source of QS waves. Over the low to the northwest, $\boldsymbol{H}_{\boldsymbol{c}}$ vectors indicate equatorward propagation. As the season advances the vectors become stronger and the configuration 

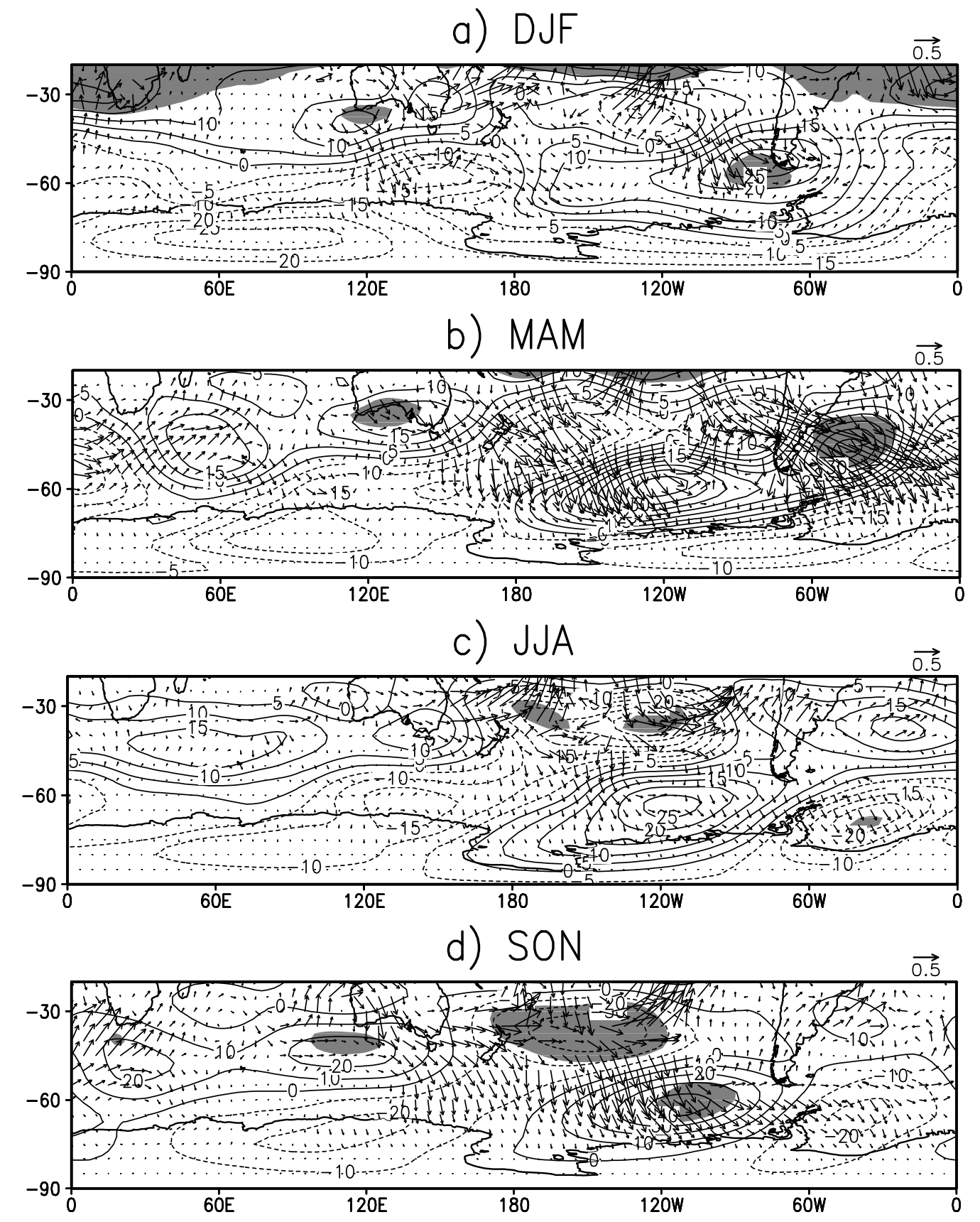

Fig. 7. Horizontal component of QS wave activity $\left(\boldsymbol{H}_{\boldsymbol{c}}\right)$ and geopotential height anomalies (El Niño minus the mean) at $300 \mathrm{hPa}$ for the El Niño composites for: (a) DJF, (b) MAM, (c) JJA, and (d) SON. Contour interval of height anomalies for (a), (b) and (c) is $5 \mathrm{~m}$, and for (d) $10 \mathrm{~m}$. Vectors are in $\mathrm{m}^{2} \mathrm{~s}^{-2}$.

(highs and lows) in the remaining three seasons is similar. A positive anomaly can be seen over southern Australia, a negative anomaly to the east and again, a positive anomaly to the southeast over southeastern Pacific. This is similar to what Karoly (1989) and Karoly et al. (1989) noted. The $\boldsymbol{H}_{\boldsymbol{c}}$ vectors in this region show a wave propagation poleward from southern Australia to the southeast and then equatorward in the vicinity of South America. To the west of South America in MAM strong divergence of $\boldsymbol{H}_{\boldsymbol{c}}$ vectors is seen, suggesting a stationary wave source. In other seasons the wave activity is weak in this region.

In the La Niña composite (Fig. 8) the height anomalies are in general opposite to those noted in the El Niño composite. Again, the wave activity, as indicated by the magnitude of the $\boldsymbol{H}_{\boldsymbol{c}}$ vector, is strong in autumn, particularly in the south $\mathrm{Pa}-$ cific. $\boldsymbol{H}_{\boldsymbol{c}}$ vectors in autumn indicate wave propagation from southern Australia to the southeast and equatorward propagation in the vicinity of South America. This path over 

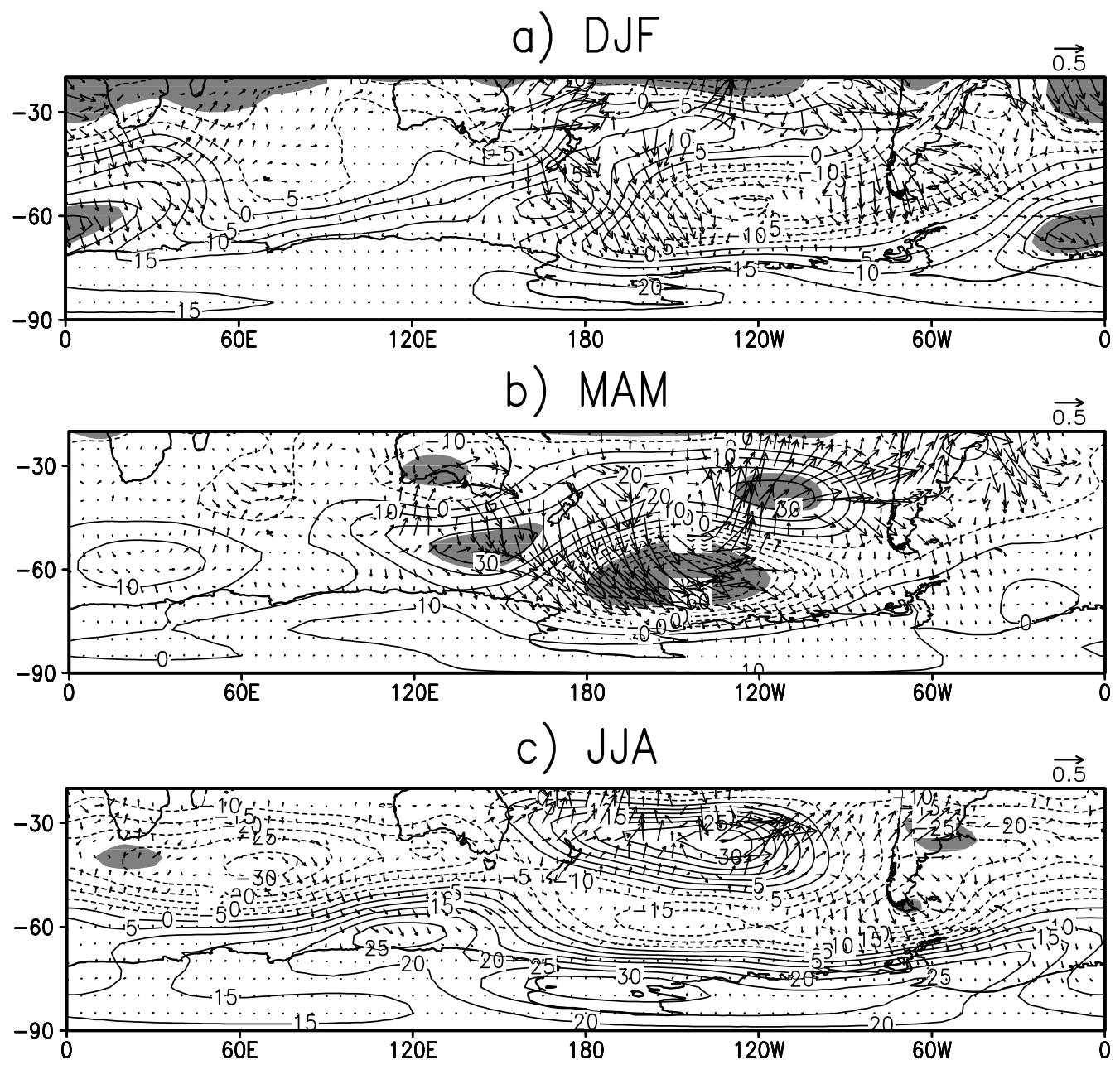

d) SON

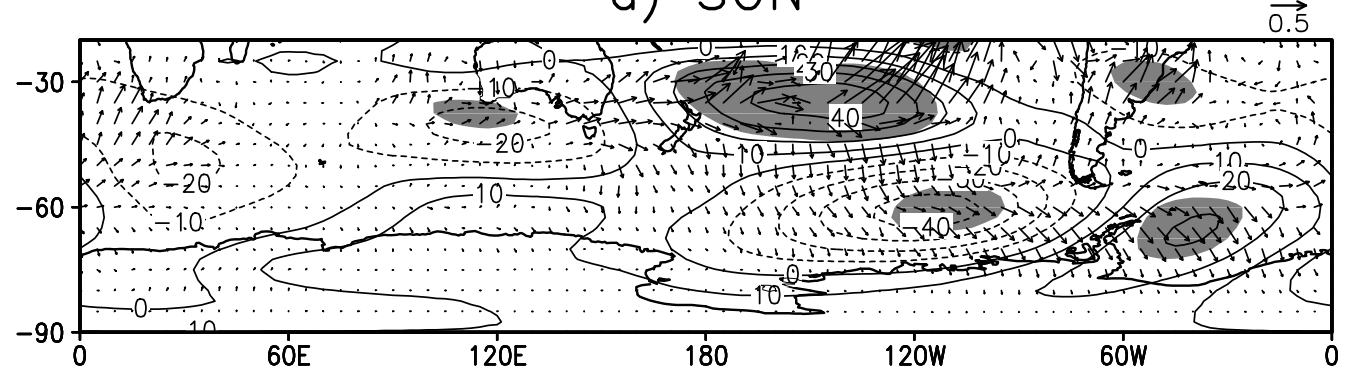

Fig. 8. Same as Fig. 7, but for the La Niña composites.

Pacific American sectors seems to be a preferred route of energy dispersion (Ambrizzi and Hoskins, 1997). The strong divergence of $\boldsymbol{H}_{\boldsymbol{c}}$ vectors to the southeast of Australia indicate a source of QS waves. In winter the wave activity is not strong. This is somewhat different from what Karoly (1989) noted. He noted the wave pattern in winter. Also Karoly (1989) used only 3 ENSO events and only for the winter and summer seasons. In the present work we use a much larger sample of ENSO events and study the wave propagation in all four seasons. Further Karoly (1989) did not discuss La Niña cases explicitly.
In both Figs. 7 and 8 the wave train is most dominant in the MAM season and less clear in other seasons. The reason for this seasonal difference is worthy of discussion. Two explanations are likely. Probably Plumb vectors are picking up the initial development in MAM in response to the SST and convection anomalies, while in winter (JJA) feedback with transients and other processes might be producing multiple energy sources, which might affect the waves such that less propagation is seen. An alternative explanation is that the MAM base state could be favoring the QS wave propagation. However, from Table 1 it can be seen that both initial and 
mature phases of El Niño events (such as 1982, 1983, 1997 and 1998) are joined together and so it is more likely that the base state in MAM could be favoring the QS wave propagation during ENSO events. Hoskins and Ambrizzi (1993) and Ambrizzi et al. (1995) have shown the importance of base state on the propagation of QS Rossby waves.

In a recent study, Renwick and Revell (1999) noted a higher incidence of blocking in the southeast Pacific during the El Niño events in the austral spring. Making numerical experiments with a linearized barotropic model they suggested that the enhanced blocking over the southeast Pacific is forced by a particular Rossby wave train triggered by an OLR anomaly (diabatic heating or upper level divergence), presumably generated during the El Niño events. Our results seem to corroborate this hypothesis. Also in Fig. 7a the center of positive anomalies is seen over the southeast Pacific. This positive center is associated with higher frequency of blocking highs in this region. In Fig. 8d a negative anomaly center can be seen. This suggests a decrease in the frequency of blocking highs in this region during the La Niña events in spring. The predisposition towards blocking over this region during the El Niño events and vice versa during the La Niña events was pointed out by Kiladis and Mo (1998) as well. However, in the present study it is shown that the formation of a positive center over southeast Pacific is associated with stationary wave propagation. The vertical component of $\boldsymbol{F}_{\boldsymbol{s}}$ for the El Niño and La Niña composites (figures not shown) did not show large differences, except that during the El Niño events there seems to be higher vertical propagation.

To see the vertical variation of the QS wave configuration, $\boldsymbol{H}_{\boldsymbol{c}}$ vectors and the height anomalies are computed for 200 and $500 \mathrm{hPa}$. These are shown in the Appendix (Figs. A3A6). The characteristics of height anomalies and $\boldsymbol{H}_{\boldsymbol{c}}$ vectors are very similar to what was seen earlier in Figs. 7 and 8 . This shows that the configuration of QS waves are essentially barotropic in nature, and a barotropic model will be able to simulate well the propagation of QS waves. Indeed, Renwick and Revell (1999) were successful in simulating QS Rossby wave propagation using a barotropic model.

\section{Summary and conclusions}

In this paper we studied the characteristics of QS waves in the SH using 49 years (1950-1998) of NCEP/NCAR reanalysis data. Earlier studies (e.g. Quintanar and Mechoso, 1995) used much less data. A comparison between the characteristics of QS waves in the 49 years data and recent data (19791998), which included satellite soundings, showed that the differences are not large and the entire 49 years of data can be used with confidence. The amplitude of QS wave 1 has two maxima, one at $30^{\circ} \mathrm{S}$ and the other at $55^{\circ} \mathrm{S}$. The maximum at $55^{\circ} \mathrm{S}$ is noted in all four seasons and this maximum is more than double that in the subtropics. The maximum in the subtropics is strongest in the austral winter, while the maximum at $55^{\circ} \mathrm{S}$ is strongest in spring. Except in summer, the QS wave 1 amplitude increases from the troposphere into the stratosphere, indicating a vertical propagation. QS waves 2 and 3 have much less amplitudes. Monthly variation of the amplitude of QS wave 1 clearly shows that it is highest in October, particularly in the upper troposphere and the lower stratosphere.

The difference between the El Niño and La Niña years and the mean showed that during the El Niño years there is an increase in the amplitude of QS 1 in winter and spring in the higher latitudes, mainly in the stratosphere. Both in winter and spring there is an increase of the amplitude of QS wave 1 in the troposphere in the subtropics. During the La Niña years there is a decrease in the amplitude of QS wave 1 in the troposphere and stratosphere in winter. A comparison of EP fluxes for El Niño and La Niña periods showed that during the El Niño period there is a stronger upward and equatorward focussing of QS waves, particularly in spring. Since the EP vectors are parallel to the direction of energy propagation, the differences between the El Niño and La Niña periods give the direction of differences in energy transport.

To examine the QS wave propagation for El Niño and La Niña periods Plumb's (1985) methodology is used. A clear wave train can be identified at $300 \mathrm{hPa}$ throughout the year, except in summer. The horizontal component of wave activity in the El Niño composite showed a Rossby wave propagation along a Rossby wave guide, at first poleward until it reaches its turning latitude in the SH midlatitudes, then equatorward in the vicinity of the South America (Hoskins and Ambrizzi, 1993). This path over the PacificAmerican sectors seems to be a prefered route of energy dispersion (Ambrizzi and Hoskins, 1997). Ambrizzi and Hoskins (1997) noted the existence of a wave guide along the South Pacific jet and into the subtropics of the South Atlantic during the austral summer. But our results show that the wave train is not clearly defined in summer.

The position of the center of positive anomalies over the southeast Pacific in Figs. 7c-d is relevant for blocking (the positive anomaly center is favorable for the occurrence of blocking highs over the southeast Pacific near South America). We also noted a center of negative anomalies in the La Niña composite (Fig. 8d). This seems to favor a reduction in the occurrence of blocking highs in this region. The relevance of these positive and negative anomaly centers during the El Niño and La Niña events is also pointed out by Kiladis and Mo (1998). But our results showed the importance of Rossby wave propagation which they did not discuss. Recently, Renwick and Revell (1999) found that the blocking frequency over the southeast Pacific increases during El Niño events. Their numerical experiments suggest that the enhanced blocking is favored by Rossby wave propagation. Thus, our results corroborate this hypothesis. 


\section{Appendix}

a) DJF

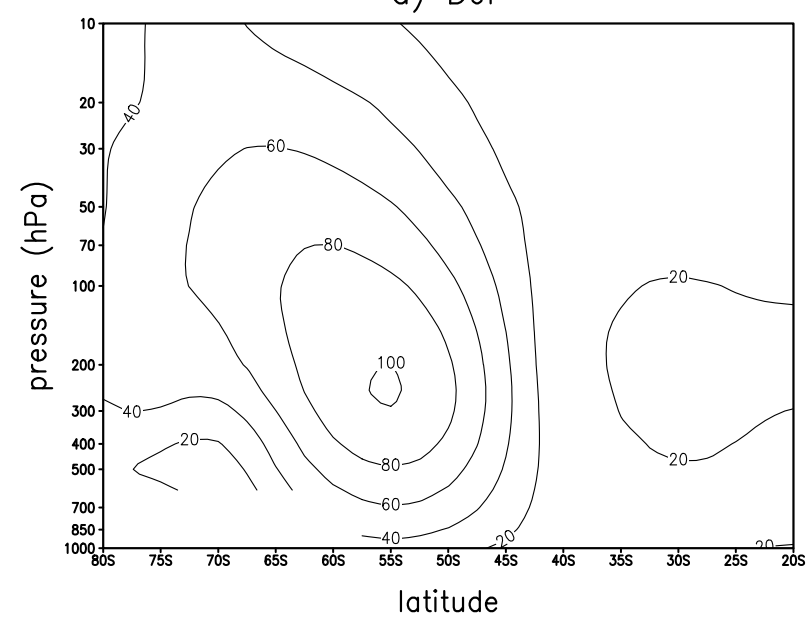

c) JJA

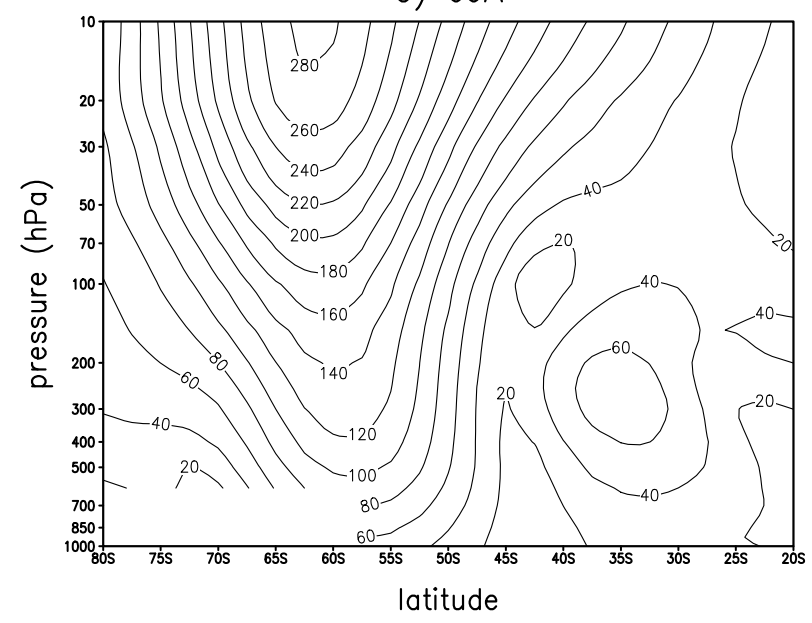

b) MAM

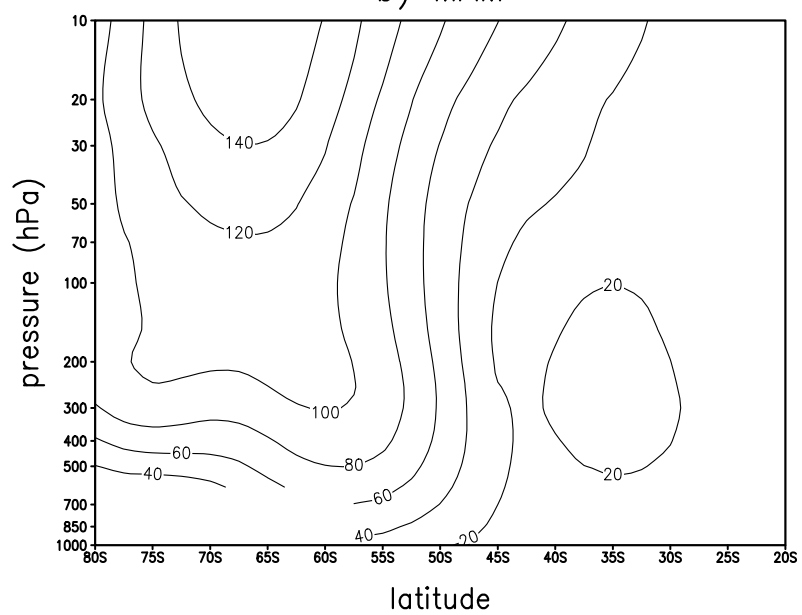

d) $\mathrm{SON}$

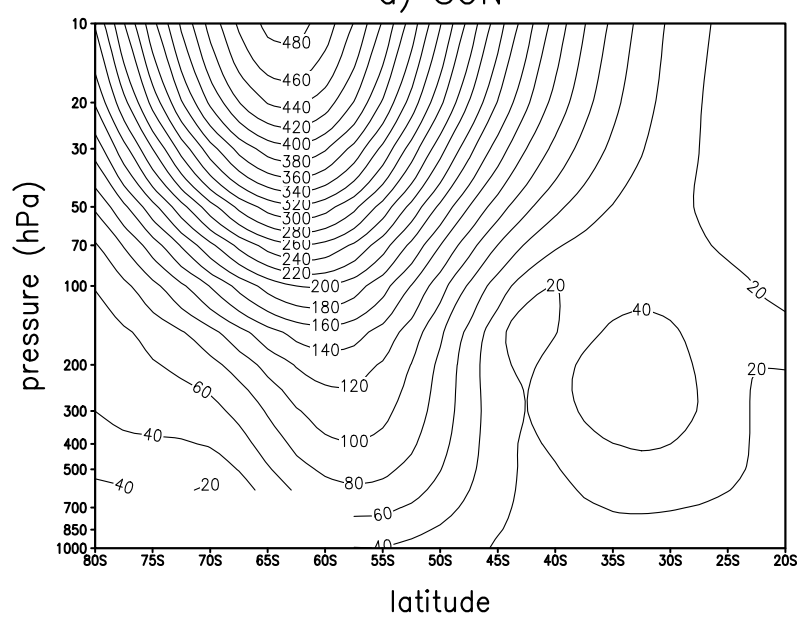

Fig. A1. Amplitudes of QS wave 1 (m) in the data set for the period 1979-1998: (a) DJF, (b) MAM, (c) JJA, and (a)d SON. Contour interval is $20 \mathrm{~m}$. 
a) DJF

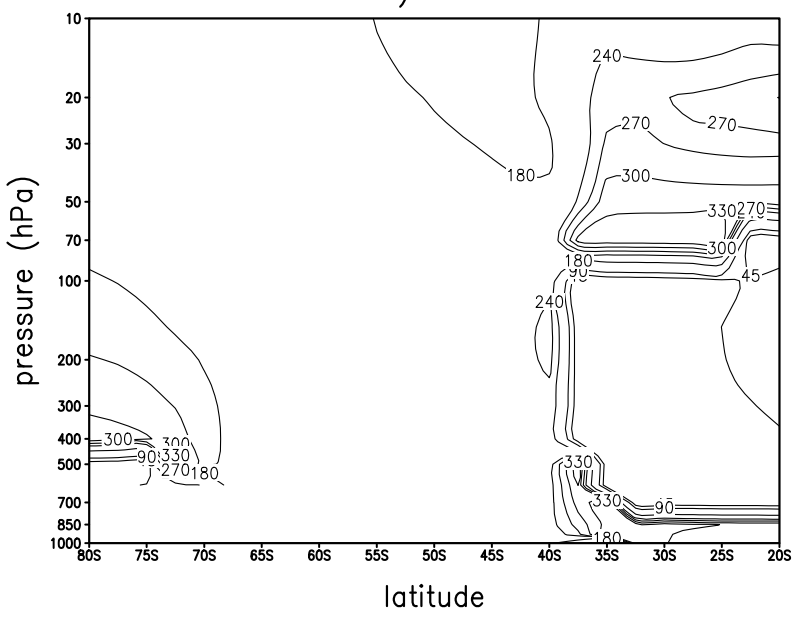

c) JJA

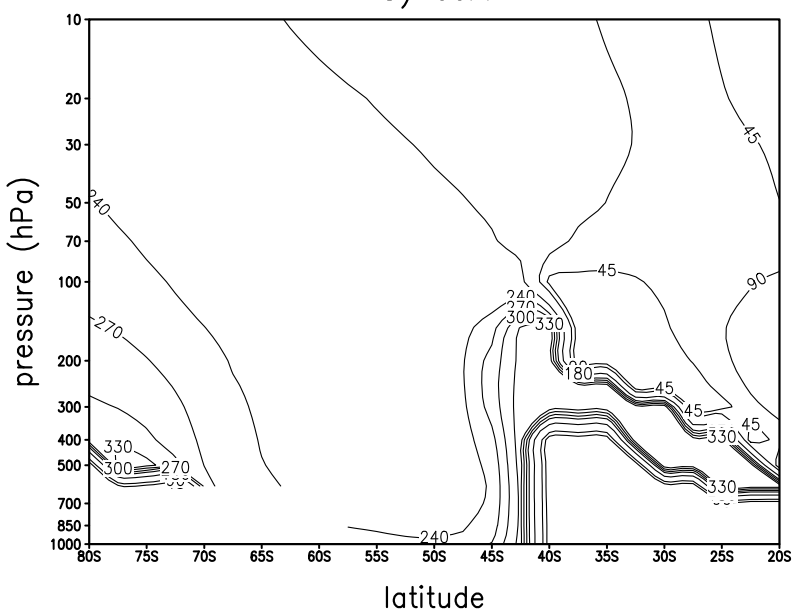

b) MAM

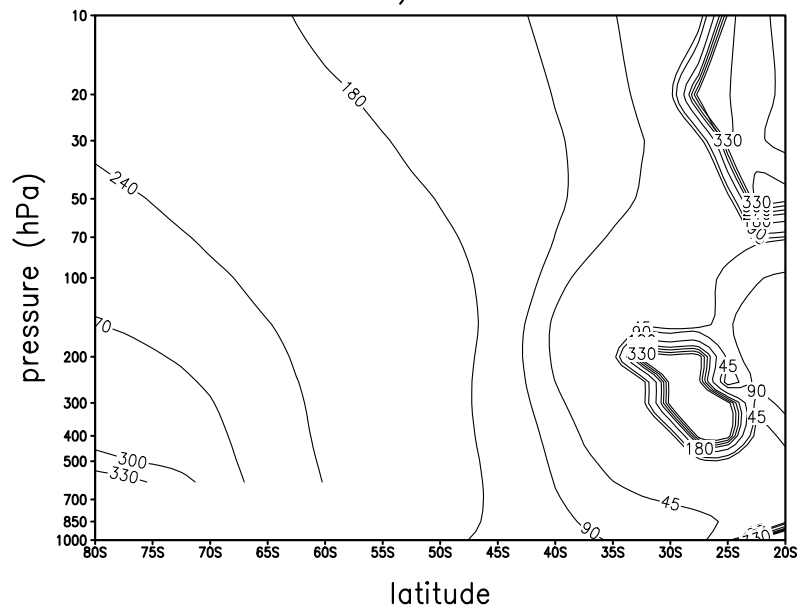

d) $\mathrm{SON}$

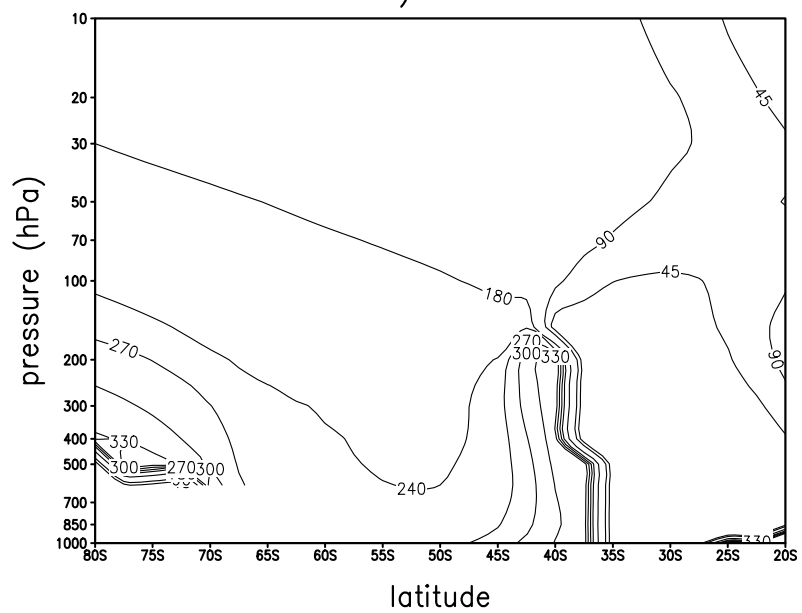

Fig. A2. Same as Fig. A1, but for the phase (degrees). 


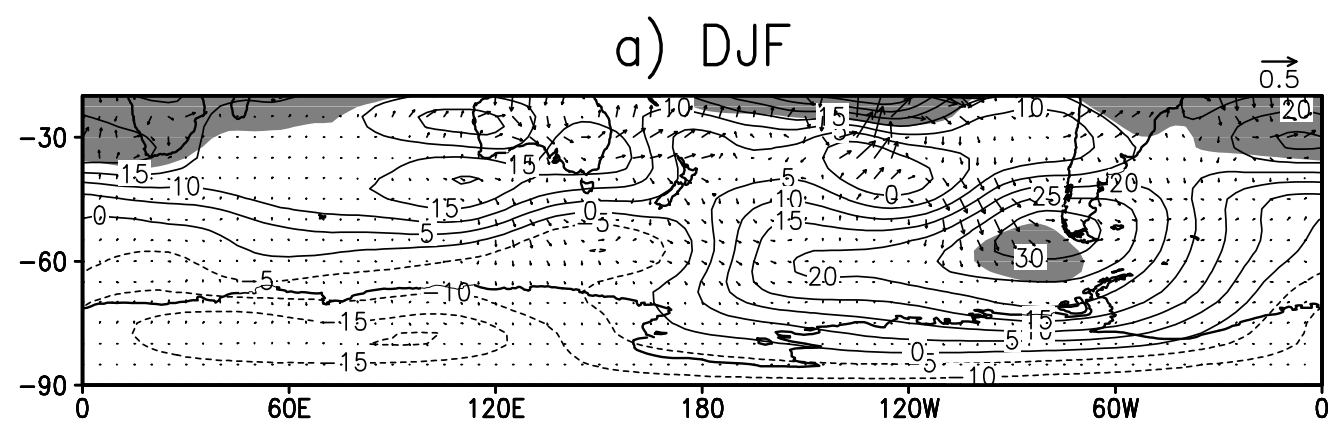

b) MAM
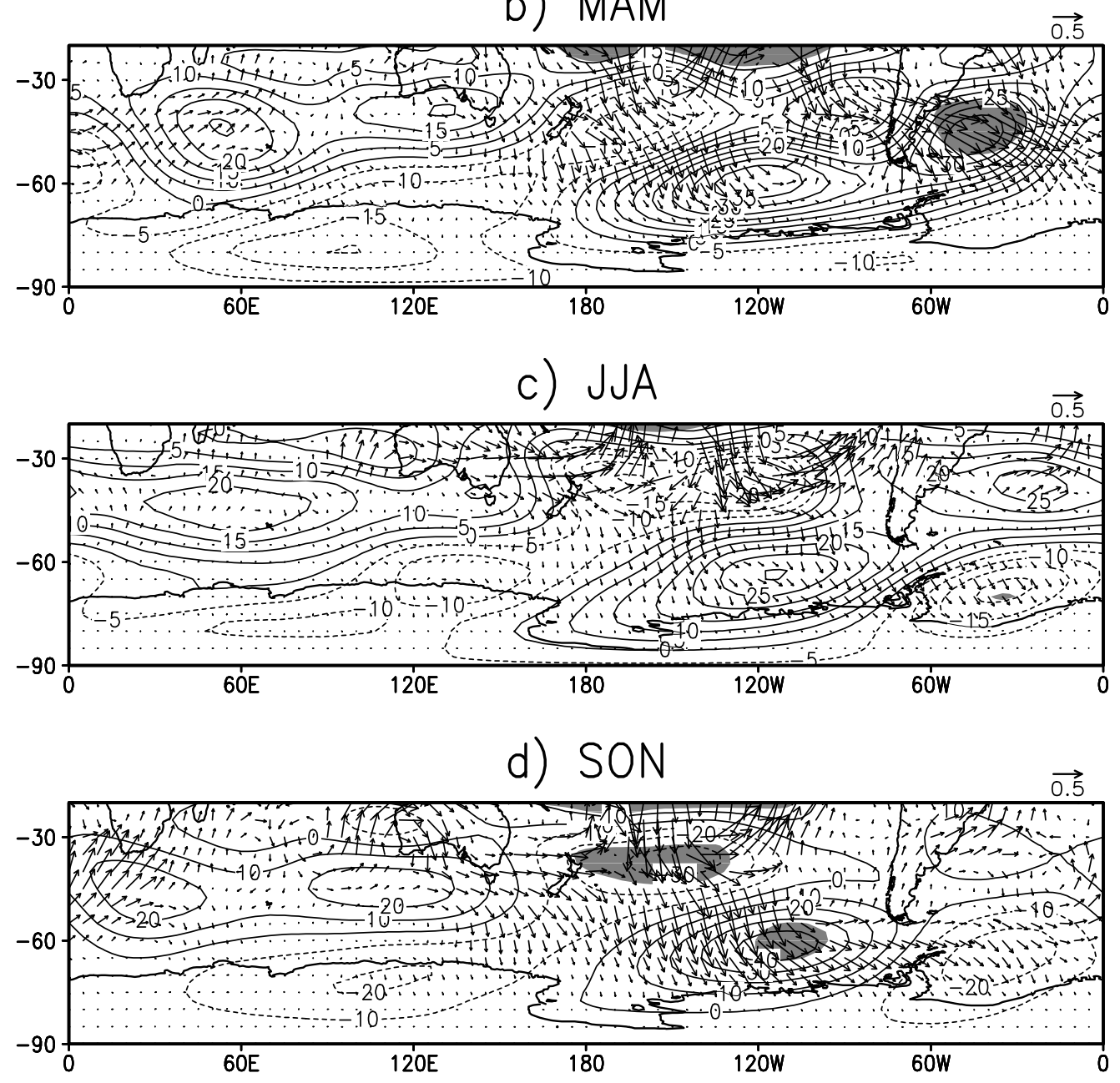

Fig. A3. Horizontal component of QS wave activity $\left(\boldsymbol{H}_{\boldsymbol{c}}\right)$ and geopotential height anomalies (El Niño minus the mean) at $200 \mathrm{hPa}$ for the El Niño composites for: (a) DJF, (b) MAM, (c) JJA, and (d) SON. Contour interval for height anomalies for (a), (b), and (c) is $5 \mathrm{~m}$ and for (d) $10 \mathrm{~m}$. Vectors are in $\mathrm{m}^{2} \mathrm{~s}^{-2}$. 

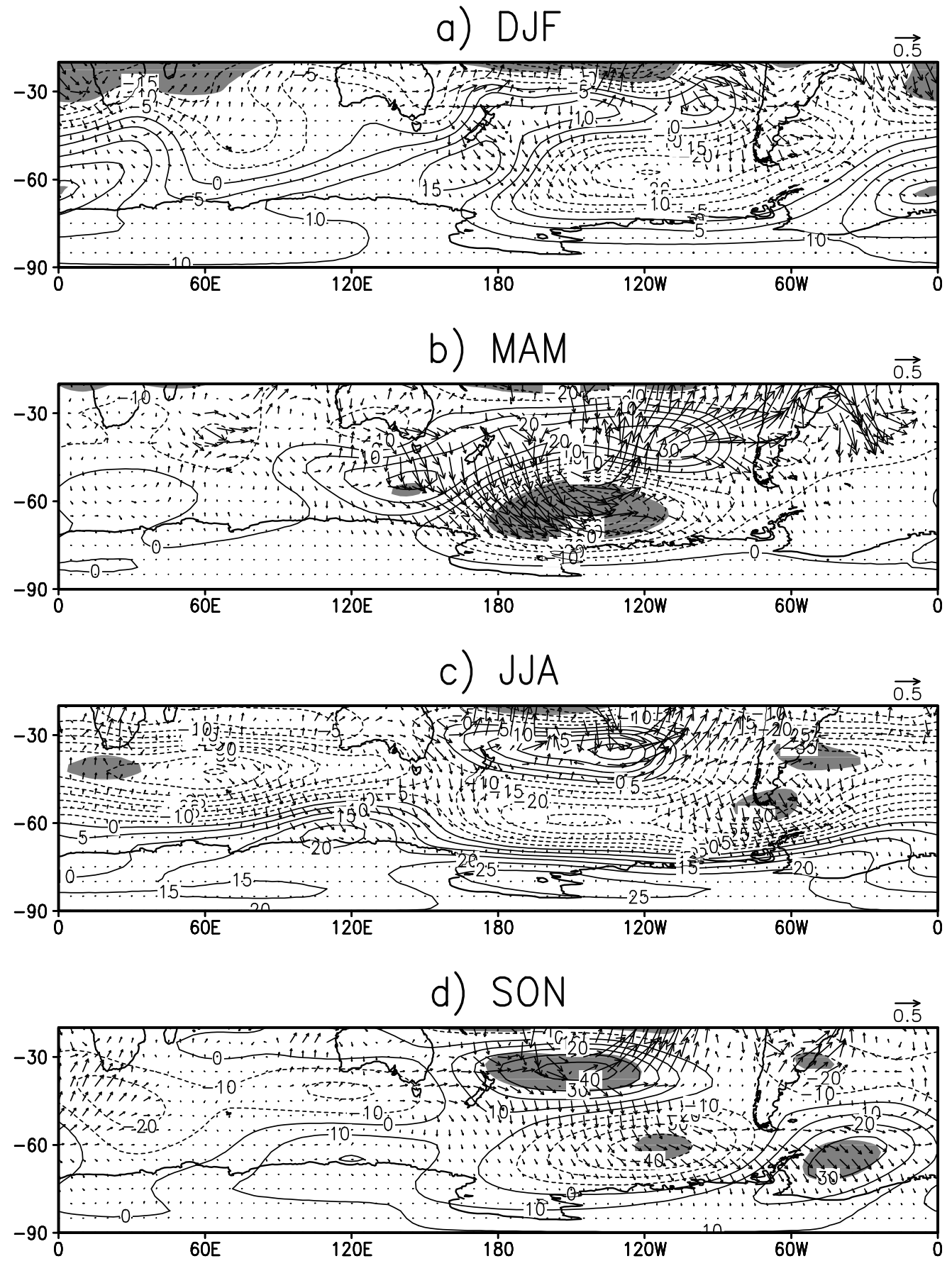

Fig. A4. Same as Fig. A3, but for the La Niña composites. 

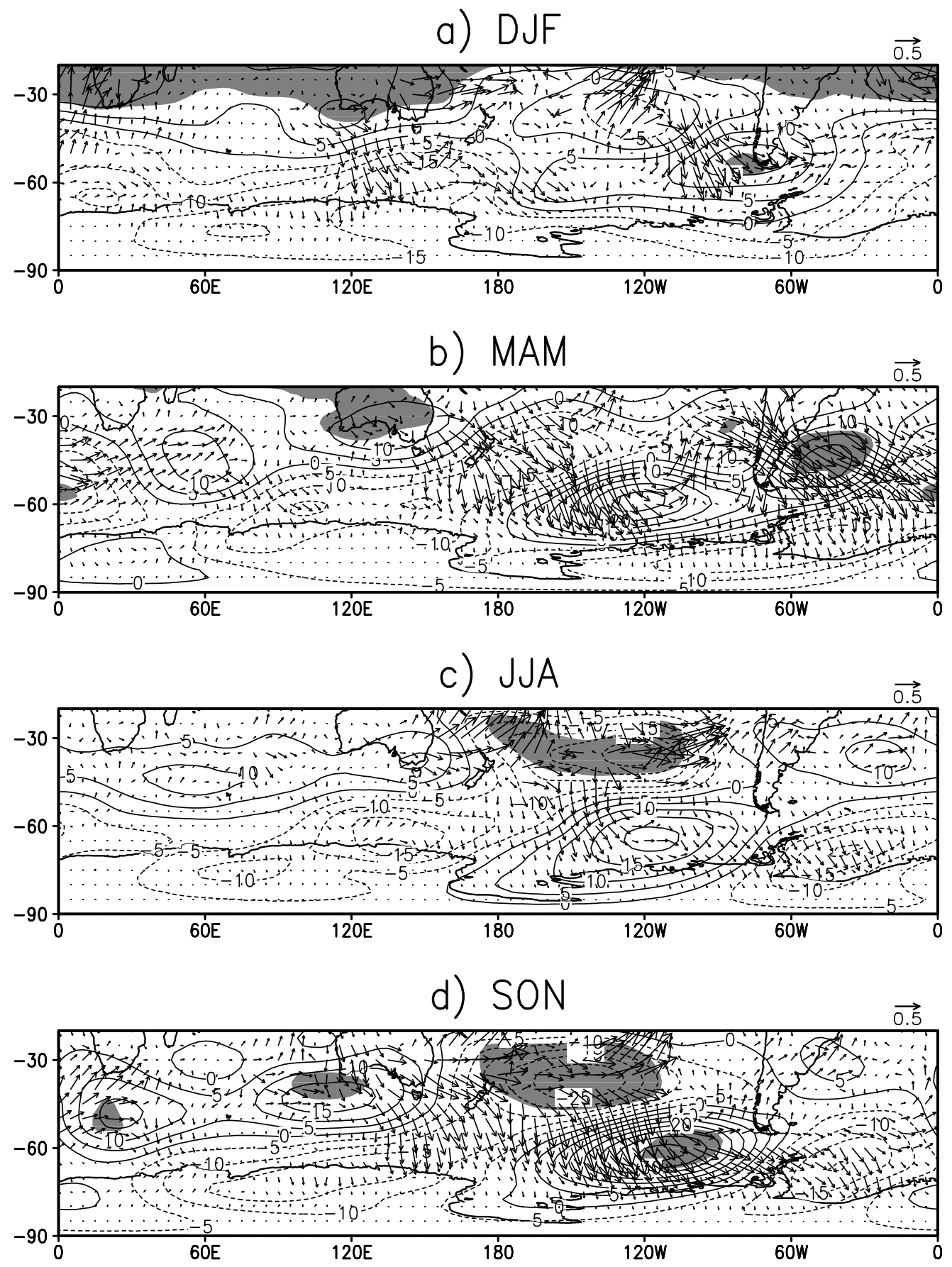

Fig. A5. Same as Fig. A3, but for $500 \mathrm{hPa}$ level. 

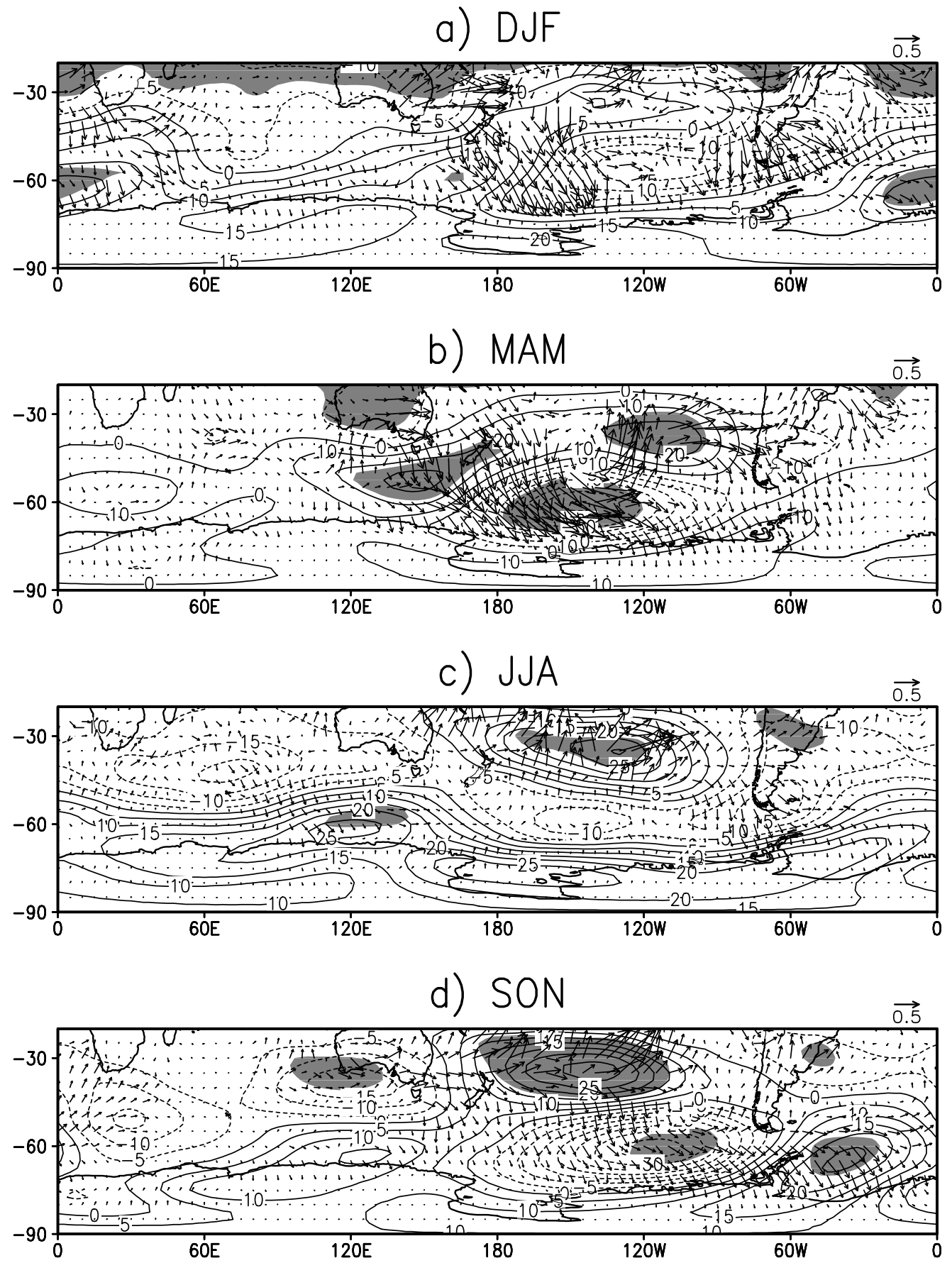

Fig. A6. Same as Fig. A3, but for the La Niña composites and for $500 \mathrm{hPa}$ level. 
Acknowledgements. One of the authors (J. P. R. Fernandez) was supported by Fundação de Amparo à Pesquisa do Estado de São Paulo (FAPESP/Processo 98/16035-6). Thanks are due to the two referees for their useful suggestions.

Topical Editor U.-P. Hoppe thanks two referees for their help in evaluating this paper.

\section{References}

Ambrizzi, T. and Hoskins, B. J.: Stationary Rossby wave propagation in a baroclinic atmosphere, Quart. J. Roy. Meteor. Soc., 123, 919-928, 1997.

Ambrizzi, T., Hoskins, B. J., and Hsu, H. H.: Rossby wave propagation and teleconnection patterns in the austral winter, J. Atmos. Sci., 52, 3661-3672, 1995 .

Charney, J. G. and Eliassen, A.: A numerical method for predicting the perturbations of the middle-latitude westerlies, Tellus, 1, 38$54,1949$.

Charney, J. G. and Drazin, P. G.: Propagation of planetary-scale disturbances from the lower into upper atmosphere, J. Geophys. Res., 66, 83-109, 1961.

Edmon, H. J., Hoskins, B. J., and McIntyre, M. E.: Eliassen-Palm cross sections for the troposphere, J. Atmos. Sci., 37, 2600-2616, 1980.

Eliassen, A. and Palm, E.: On the transfer of energy in stationary mountain waves. Geofys. Publ., 22, No. 3, 1-23, 1961.

Hartman, D. L.: Stationary planetary waves in the Southern Hemisphere, J. Geophys. Res., 82, 4930-4934, 1977.

Holopainen, E. O.: On the dynamic forcing of the long term flow by large-scale Reynold's stresses in the atmosphere, J. Atmos. Sci., 35, 1596-1604, 1978.

Holopainen, E. O., Rontu, L., and Lau, N.-C.: The effect of largescale transient eddies on the mean flow in the atmosphere, J. Atmos. Sci., 39, 1702-1984, 1982.

Hoskins, B, J. and Ambrizzi, T.: Rossby wave propagation on a realistic longitudinally varying flow, J. Atmos. Sci., 50, 1661$1671,1993$.

Hurrell, J. W., van Loon, H., and Shea, D. J.: The mean state of the troposphere, in: Meteorology of the Southern Hemisphere, editd by Karoly, D. J. and Vincent, D. G., Meteorological Monographs, American Meteorological Society, 1-46, 1998.

Kalnay, E., Kanamitsu, M., and Kistler, R. et al.: The NCEP/NCAR 40-year reanalysis project, Bull. Amer. Meteor. Soc., 77, 437471,1996
Karoly, D. J.,: Southern Hemisphere circulation features associated with El-Niño-southern oscillation events, J. Climate, 2, 1239$1252,1989$.

Karoly, D. J., Plumb, R. A., and Ting, M.: Examples of horizontal propagation of quasi-stationary waves, J. Atmos. Sci., 46, 28022811, 1989.

Kiladis. G. N. and Mo, K. G.: Interannual and intraseasonal variability in the Southern Hemisphere, in: Meteorology of the Southern Hemisphere, edited by Karoly, D. J. and Vincent, D. G., Meteorological Monographs, American Meteorological Society, 307-336, 1998.

Lau, K. M. and Peng, L.: Dynamics of atmospheric teleconnections during the northern summer, J. Climate, 5, 140-158, 1992.

Marques, R. F. C. and Rao, V. B.: Interannual variations of blockings in the Southern Hemisphere and their energetics, J. Geophys. Res., 105, D4, 4625-4636, 2000.

Mechoso, C. R. and Hartman, D. L.: An observational study of travelling planetary waves in the Southern Hemisphere, J. Atmos. Sci, 39, 1921-1935, 1982.

Plumb, R. A.: On the three-dimensional propagation of stationary waves, J. Atmos. Sci., 42, 217-229, 1985.

Quintanar, A. I. and Mechoso, C. R.: Quasi-stationary waves in the Southern Hemisphere, Part I: Observational data, J. Climate, 8, 2659-2672, 1995.

Randel, W. J.: A evaluation of winds from geopotential height data in the stratosphere, J. Atmos. Sci., 44, 3097-3120, 1987.

Randel, W. J.: The seasonal evolution of planetary waves in the Southern Hemisphere stratosphere and troposphere, Quart, J. Roy. Meteor. Soc., 114, 1385-1409, 1988.

Renwick, J. A. and Revell, M. J.: Blocking over the South Pacific and Rossby wave propagation, Mon. Wea. Rev., 127, 2233-2247, 1999.

Rutllant, J. and Fuenzalida, H.: Synoptic aspects of the central Chile rainfall variability associated with the southern oscillation, Int. J. Climatol., 11, 63-76, 1991.

Schubert, S. D., Suarez, M., Park, C.-K , and Moorthi, S. GCM simulations of intraseasonal variability in the Pacific/North American region, J. Atmos. Sci., 50, 1991-2007, 1993.

Smagorinsky, J.: The dynamical influences of large scale heat sources and sinks on the quasi-stationary mean motions of the atmosphere, Quart. J. Roy. Meteor. Soc., 79, 342-366, 1953.

Trenberth, K. E.: Planetary waves at $500 \mathrm{hPa}$ in the Southern Hemisphere, Mon. Wea. Rev., 108, 1378-1389, 1980.

van Loon, H. and Jenne, R. L.: The zonal harmonic standing waves in the Southern Hemisphere, J. Geophys. Res., 77, 992-1003, 1972. 